\title{
Sensitivity of Estimated Total Canopy SIF Emission to Remotely Sensed LAI and BRDF Products
}

\author{
Zhaoying Zhang, ${ }^{1,2,3}$ Yongguang Zhang $\mathbb{D}^{1,3,4}$ Jing M. Chen, ${ }^{5}$ Weimin Ju, ${ }^{1,3}$ \\ Mirco Migliavacca $\mathbb{D}^{6}{ }^{6}$ and Tarek S. El-Madany ${ }^{6}{ }^{6}$ \\ ${ }^{1}$ International Institute for Earth System Sciences, Nanjing University, Nanjing, Jiangsu, China \\ ${ }^{2}$ Yuxiu Postdoctoral Institute, Nanjing University, Nanjing, Jiangsu, China \\ ${ }^{3}$ Jiangsu Provincial Key Laboratory of Geographic Information Science and Technology, Key Laboratory for Land Satellite Remote \\ Sensing Applications of Ministry of Natural Resources, School of Geography and Ocean Science, Nanjing University, Nanjing, \\ Jiangsu, China \\ ${ }^{4}$ Huangshan Park Ecosystem Observation and Research Station, Ministry of Education, China \\ ${ }^{5}$ Department of Geography and Planning, University of Toronto, Toronto, Ontario, Canada \\ ${ }^{6}$ Max Planck Institute for Biogeochemistry Department Biogeochemical Integration, Germany
}

Correspondence should be addressed to Yongguang Zhang; yongguang_zhang@nju.edu.cn

Received 19 December 2020; Accepted 11 August 2021; Published 17 September 2021

Copyright (c) 2021 Zhaoying Zhang et al. Exclusive Licensee Aerospace Information Research Institute, Chinese Academy of Sciences. Distributed under a Creative Commons Attribution License (CC BY 4.0).

Remote sensing of solar-induced chlorophyll fluorescence (SIF) provides new possibilities to estimate terrestrial gross primary production (GPP). To mitigate the angular and canopy structural effects on original SIF observed by sensors ( SIF $_{\text {obs }}$ ), it is recommended to derive total canopy SIF emission $\left(\mathrm{SIF}_{\text {total }}\right)$ of leaves within a canopy using canopy interception $\left(i_{0}\right)$ and reflectance of vegetation $\left(R_{\mathrm{V}}\right)$. However, the effects of the uncertainties in $i_{0}$ and $R_{\mathrm{V}}$ on the estimation of SIF total have not been well understood. Here, we evaluated such effects on the estimation of GPP using the Soil-Canopy-Observation of Photosynthesis and the Energy balance (SCOPE) model. The SCOPE simulations showed that the $R^{2}$ between GPP and SIF total was clearly higher than that between GPP and $\operatorname{SIF}_{\text {obs }}$ and the differences in $R^{2}\left(\Delta R^{2}\right)$ tend to decrease with the increasing levels of uncertainties in $i_{0}$ and $R_{\mathrm{V}}$. The resultant $\Delta R^{2}$ decreased to zero when the uncertainty level in $i_{0}$ and $R_{\mathrm{V}}$ was $\sim 30 \%$ for red band SIF (RSIF, $683 \mathrm{~nm}$ ) and $\sim 20 \%$ for far-red band SIF (FRSIF, $740 \mathrm{~nm}$ ). In addition, as compared to the TROPOspheric Monitoring Instrument (TROPOMI) $\mathrm{SIF}_{\text {obs }}$ at both red and far-red bands, $\mathrm{SIF}_{\text {total }}$ derived using any combination of $i_{0}$ (from MCD15, VNP15, and CGLS LAI products) and $R_{\mathrm{V}}$ (from MCD34, MCD19, and VNP43 BRDF products) showed comparable improvements in estimating GPP. With this study, we suggest a way to advance our understanding in the estimation of a more physiological relevant SIF datasets $\left(\mathrm{SIF}_{\text {total }}\right)$ using current satellite products.

\section{Introduction}

Recently, solar-induced chlorophyll fluorescence (SIF) has been shown to be a good indicator of terrestrial gross primary production (GPP) [1-3]. Over the past decade, many efforts have been devoted into the satellite SIF retrievals using existing instruments such as the Japanese Greenhouse Gases Observing Satellite (GOSAT), the Global Ozone Monitoring Experiment-2 (GOME-2), the Orbiting Carbon Observatory-2/3 (OCO-2/3), the TROPOspheric Monitoring Instrument (TROPOMI), and the Chinese Carbon Dioxide Observation Satellite Mission (TanSat) [4-10]. These satellite SIF data have been increasingly used to estimate global terrestrial GPP in two different approaches: constraining process-based biosphere models [11-14] and establishing the empirical relationship between GPP and SIF $[2,3,15,16]$.

However, only a portion of fluorescence, which is originally emitted by chlorophyll-a molecules in the photosynthesis system [17, 18], escapes from canopies and then is observed by sensors $\left(\mathrm{SIF}_{\mathrm{obs}}\right)$ in a particular observation direction [19-21]. The difference in escape probability among biomes could also cause the difference in the GPP$\mathrm{SIF}_{\text {obs }}$ relationship. For example, SIF escapes less from 
needle leaf forest than broadleaf forest canopies due to the higher clumping effect of needle leaf forest [22], and this difference in SIF escape probability between these two types of forests should be considered in the relationship between GPP and SIF $_{\text {obs }}$.

Therefore, it is required to estimate the total canopy SIF emission $\left(\mathrm{SIF}_{\text {total }}\right)$ to mitigate the canopy structural and angular effects on the estimation of GPP from satellite SIF data $[20,23-26]$. Several studies have proposed methods to derive SIF $_{\text {total }}$ from SIF $_{\text {obs }}$ using statistically based approaches, such as random forest algorithm [23], and physically based approaches, such as the spectral invariant theory that requires canopy interception $\left(i_{0}\right)$ and canopy reflectance of vegetation $\left(R_{\mathrm{V}}\right)[19,25]$. Regardless of statistically or physically based approaches, auxiliary data such as MERIS Terrestrial Chlorophyll Index (MTCI) and canopy reflectance at bands of $685 \mathrm{~nm}, 710 \mathrm{~nm}$, and $785 \mathrm{~nm}$ are required by Liu et al. [23] and near-infrared reflectance of vegetation $\left(\mathrm{NIR}_{\mathrm{V}}\right)$ and leaf area index $(\mathrm{LAI})$ are required by Zhang et al. [26]. Due to its simplicity and efficiency in deriving $\mathrm{SIF}_{\text {total }}$, the approach based on $\mathrm{NIR}_{\mathrm{V}}$ and $i_{0}$ has been adopted by Zhang et al. [26] to derive global SIF $_{\text {total }}$ from OCO-2 $\mathrm{SIF}_{\mathrm{obs}}$. A more consistent relationship between GPP and $\mathrm{SIF}_{\text {total }}$ across $\mathrm{C}_{3}$ plants is established, demonstrating the advantage of SIF total for global GPP estimation.

Although better relationships of SIF $_{\text {total }}$ with GPP than SIF $_{\text {obs }}$ have been reported for TROPOMI [20] and OCO-2 SIF [26], uncertainties in the above-mentioned satellite products are still considerable, which could impact the relationships between GPP and SIF $_{\text {total }}$. Currently, the trade-off between the advantage of accounting for the escape probability and the disadvantage of the uncertainty in the auxiliary data has not been well investigated to better understand the

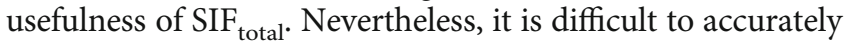
estimate the uncertainties for all satellite products. As a powerful tool, the Soil-Canopy-Observation of Photosynthesis and the Energy balance (SCOPE) model [27] can capture the physical mechanisms behind photosynthesis and fluorescence, and it has been extensively used in the community of SIF remote sensing [28-31]. Therefore, the SCOPE model can be used to simulate the uncertainty effect on the relationships between GPP and SIF $_{\text {total }}$ by artificially adding random uncertainty.

The fluorescence spectrum emitted by chlorophyll-a molecules in the $650-850 \mathrm{~nm}$ range has two peaks in the red ( $685 \mathrm{~nm}, \mathrm{RSIF})$ and far-red $(\sim 740 \mathrm{~nm}, \mathrm{FRSIF})[17,18$, 32]. Both RSIF and FRSIF originate from photosystem I (PS I) and photosystem II (PS II) [17]. RSIF is mainly from PS II, which is better linked to photochemical quenching and nonphotochemical quenching $[33,34]$. As expected, RSIF should be more sensitive to GPP than FRSIF [35]. This is supported by a global sensitivity analysis of the SCOPE model [36]. In addition, Zhang et al. [37] also reported that RSIF shows better seasonal correlation with photosynthesis than FRSIF from Scots pine at the leaf scale during the spring recovery of photosynthesis. Furthermore, canopy SIF $_{\text {total }}$ at both red $\left(\mathrm{RSIF}_{\text {total }}\right)$ and far-red band $\left(\mathrm{FRSIF}_{\text {total }}\right)$ has also been investigated with field observations [24, 38], but their performance in estimating GPP has not been inves- tigated and compared with satellite observations. Moreover, the signal of RSIF is weaker than that of FRSIF due to the stronger reabsorption of pigments, which reduces the retrieval accuracy of RSIF compared to FRSIF [9, 39].

In this work, the main objectives are (1) to investigate the effect of uncertainties in $i_{0}$ and $R_{\mathrm{V}}$ on the relationships between GPP and SIF total based on the SCOPE model simulations and (2) to evaluate the sensitivity of estimated SIF total to uncertainties in multiple satellite LAI and BRDF products.

\section{Materials and Methods}

2.1. TROPOMI SIF Data. Both RSIF and FRSIF from TROPOMI were used in this study (ftp://fluo.gps.caltech.edu/ data/). The Sentinel 5 Precursor (S-5P) satellite with a single payload of TROPOMI was launched on 13 October 2017 on a near-polar, sun-synchronous orbit. The repeat cycle in the nadir direction is 17 days, and the overpass time at equator is $\sim 13: 30$ local time. S-5P has a varying across track spatial resolutions of $3.5-14 \mathrm{~km}$ according to pixel position but a fixed along track spatial resolution of $7.2 \mathrm{~km}(5.6 \mathrm{~km}$ after 6 August 2019). Recently, TROPOMI SIF has been successfully retrieved using a data-driven approach based on a singular value decomposition technique in the atmospheric windows of $663-685.3 \mathrm{~nm}$ for RSIF [39] and 743-758 nm for FRSIF [9]. Details about the retrieval process can be referred to Köhler et al. [9] and Köhler et al. [39] and hence not shown here for simplicity.

2.2. Derivation of Total Canopy SIF Emission at the Photosystem Level $\left(S I F_{\text {total }}\right)$. A full description of the theoretical basis behind the derivation of SIF $_{\text {total }}$ can be found in recent studies $[19,20,25,40]$. Only a brief description is presented here. The escape probability of fluorescence from leaf surface to canopy $\left(f_{\mathrm{LC}}\right)$ for dense canopies and black soil can be approximately estimated as follows [19]:

$$
f_{\mathrm{LC}}=\frac{R_{\lambda}}{i_{0} \times \omega_{\lambda}},
$$

where $R_{\lambda}$ is the bidirectional reflectance factor in the same wavelength $(\lambda)$ and observation direction as $\operatorname{SIF}_{\text {obs }}$ and $\omega_{\lambda}$ is leaf albedo (leaf reflectance + transmittance). To reduce soil effects on $R_{\lambda}$ for sparse canopies, Zeng et al. [25] proposed to replace $R_{\lambda}$ at near-infrared band with nearinfrared reflectance of vegetation $\left(\mathrm{NIR}_{\mathrm{V}}\right)$, which is the product of reflectance in near-infrared band and normalized difference vegetation index (NDVI) [41]:

$$
\begin{aligned}
& \mathrm{NIR}_{\mathrm{V}}=\mathrm{NDVI} \times R_{\mathrm{nir}}, \\
& \mathrm{NDVI}=\frac{R_{\mathrm{nir}}-R_{\mathrm{red}}}{R_{\mathrm{nir}}+R_{\mathrm{red}}},
\end{aligned}
$$

where $R_{\text {nir }}$ and $R_{\text {red }}$ are the reflectance at near-infrared and red bands, respectively. Similarly, red reflectance of vegetation $\left(\operatorname{Red}_{\mathrm{V}}\right)$ was calculated with $R_{\text {red }}$ and NDVI [24]:

$$
\operatorname{Red}_{\mathrm{V}}=\mathrm{NDVI}^{2} \times R_{\text {red }} \cdot
$$




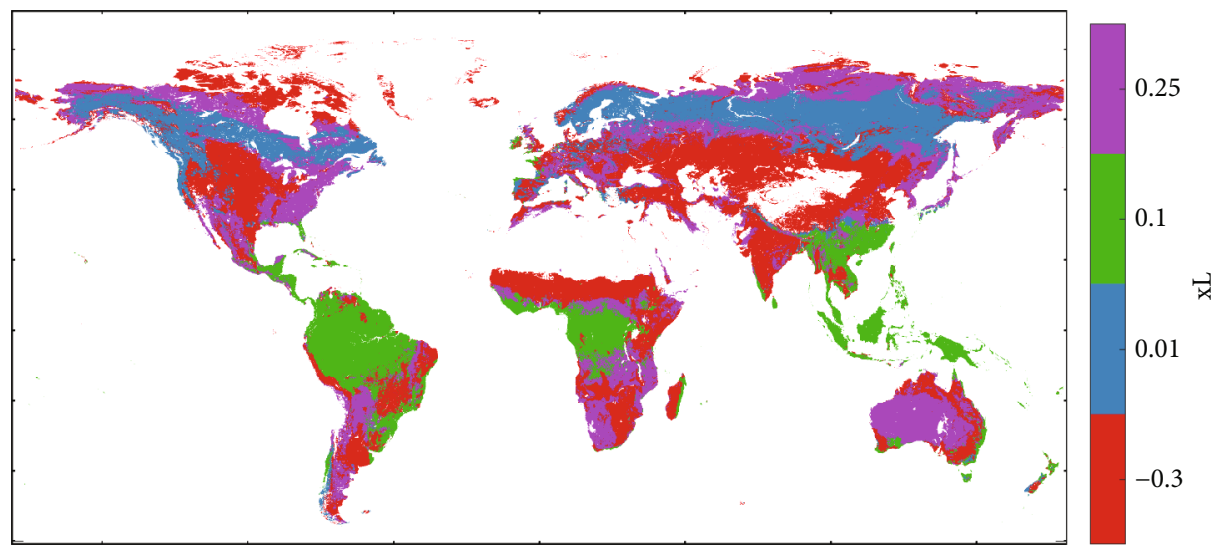

FIGURE 1: The spatial map of xL based on MODIS plant functional type classification (MCD12Q1) according to the biome-specific value used in the Common Land Model 4.5 (CLM 4.5). xL represents the departure of leaf angles from a random distribution.

To avoid confusion, $R_{\text {red }}$ is the reflectance of whole canopy (vegetation + soil) in the red band and $\operatorname{Red}_{\mathrm{V}}$ is the reflectance of vegetation in the red band. Since no corresponding reflectance data is currently available for satellite SIF at the same sun-viewing geometry as SIF, the RossThick-LiSparseR (RTLSR) BRDF model can be used to simulate reflectance at red and near-infrared bands that can be further used to calculate $\operatorname{Red}_{\mathrm{V}}$ and $\mathrm{NIR}_{\mathrm{V}}$. Therefore, $\operatorname{Red}_{\mathrm{V}}$ and $\mathrm{NIR}_{\mathrm{V}}$ can be used as $R_{\lambda}$ in Equation (1) for calculating $f_{\text {LC }}$ for RSIF and FRSIF, respectively. Parameters to drive the RTLSR BRDF model can be available from existing BRDF products and details are presented in Section 2.3. $i_{0}$ is commonly calculated with G-function $(G)$, leaf area index (LAI), clumping index (CI), and solar zenith angle (SZA, $\theta$ ) as follows [42]:

$$
\begin{aligned}
i_{0} & =1-\operatorname{EXP}\left(\frac{-G(\theta) \times \mathrm{LAI} \times \mathrm{CI}}{\cos \theta}\right), \\
G(\theta) & =\phi_{1}+\phi_{2} \times \cos \theta, \\
\phi_{1} & =0.5-0.663 \chi_{L}-0.33 \chi_{L}^{2}, \\
\phi_{2} & =0.877\left(1-2 \phi_{1}\right),
\end{aligned}
$$

where the empirical derived parameters $\phi_{1}$ and $\phi_{2}$ are dependent on $\chi_{L}$, which is the departure of leaf angles from a random distribution, and $\chi_{L}$ is assigned as biome-specific values based on the Common Land Model 4.5 (CLM 4.5) [43]. We derive the global values of $\chi_{L}$ based on MODIS plant functional type classification (MCD12Q1), and the spatial maps of $\chi_{L}$ can be found in Figure 1. The CI data was from He et al. [22]. Details of LAI products used in this study are presented in Section 2.4. The sensitivities of the calculation of $\mathrm{SIF}_{\text {total }}$ to different BRDF and LAI products were systematically evaluated to serve as a reference for the calculation of satellite SIF $_{\text {total }}$.

To derive SIF $_{\text {total }}$ at the photosystem level, the escape probability of fluorescence from photosystem to the leaf surface $\left(f_{\mathrm{PL}}\right)$ was introduced [24]. Therefore, the escape probability of SIF $\left(f_{\mathrm{PC}}\right.$ or $\left.f_{\text {esc }}\right)$ from photosystem level to canopy level in any direction is calculated as follows:

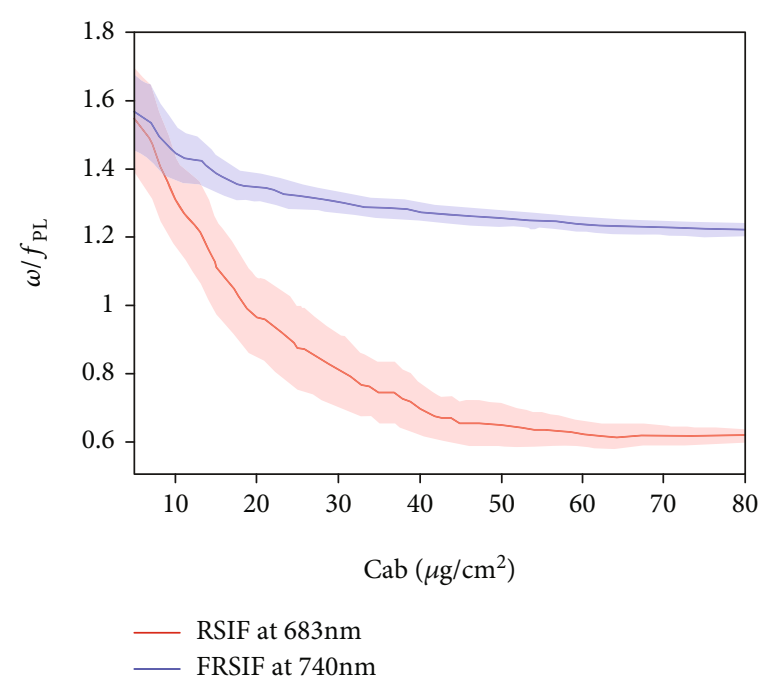

Figure 2: The relationships between $\mathrm{Cab}$ and the ratio of leaf albedo $(\omega)$ to the escape probability of fluorescence from photosystem to leaf surface $\left(f_{\mathrm{PL}}\right)$ at $683 \mathrm{~nm}$ (red) and $740 \mathrm{~nm}$ (blue) based on the SCOPE model simulation.

$$
f_{\mathrm{esc}}=\frac{f_{\mathrm{PL}} \times f_{\mathrm{LC}}}{\pi}=\frac{R_{\lambda} \times f_{\mathrm{PL}}}{\pi \times i_{0} \times \omega_{\lambda}}=\frac{R_{\lambda}}{\pi \times i_{0} \times K_{\lambda}},
$$

Both $\omega_{\lambda}$ and $f_{\mathrm{PL}}$ are negatively related to the absorptance of pigments, such as chlorophylls $\mathrm{a}+\mathrm{b}(\mathrm{Cab})$. In other words, high Cab causes low $\omega_{\lambda}$ and $f_{\mathrm{PL}}$, and vice versa. To simplify Equation (5), we define $K_{\lambda}$ as the ratio of $\omega_{\lambda}$ to $f_{\mathrm{PL}}$ and assume $K_{\lambda}$ can be roughly estimated with Cab. Based on SCOPE model simulations (see Section 2.6), $K_{\lambda}$ for RSIF at $683 \mathrm{~nm}$ quickly decreased with Cab and started to saturate when $\mathrm{Cab}>40 \mu \mathrm{g} / \mathrm{cm}^{2}$ (Figure 2). In comparison, $K_{\lambda}$ for FRSIF at $740 \mathrm{~nm}$ showed less variations within the ranges of 1.2-1.6. Due to the lack of accurate Cab information, we simply set $K_{\lambda}$ as 0.6 and 1.2 for RSIF and FRSIF, respectively, which are suitable for a wide range of Cab. 
TABLE 1: Information about the three BRDF products used in this study.

\begin{tabular}{lccc}
\hline Short name & MCD43 & MCD19 & VNP43 \\
\hline Product name & MCD43A1 & MCD19A3 & VNP43IA1 \\
Version & V006 & V006 & V001 \\
Input data & MOD09GA & MYD02 & VNP09GA \\
Equatorial crossing time & MYD09GA & $10: 30 \& 13: 30$ & VNP39GA \\
Temporal coverage & $10: 30 \& 13: 30$ & $2000-$ & $13: 30$ \\
Global coverage interval & $2000-$ & 8 -day & $2012-$ \\
Spatial resolution & Daily & 1 km & Daily \\
Reference & $500 \mathrm{~m}$ & {$[45,46]$} & $500 \mathrm{~m}$ \\
Data source & {$[44,74]$} & WWW1 & {$[71,73]$} \\
\hline
\end{tabular}

Note: WWW1: search.earthdata.nasa.gov.

Finally, SIF total at the photosynthesis level can be calculated as follows:

$$
\mathrm{SIF}_{\text {total }}=\frac{\operatorname{SIF}_{\mathrm{obs}}}{f_{\mathrm{esc}}}
$$

2.3. Bidirectional Reflectance Distribution Function (BRDF) Parameter Products. To be consistent with the same sunviewing geometry as TROPOMI SIF, reflectance at red and far-red bands was simulated using the semiempirical models required for $\operatorname{Red}_{\mathrm{V}}$ and $\mathrm{NIR}_{\mathrm{V}}$ calculation, such as RossThickLiSparseR (RTLSR) as follows:

$$
R(\theta, v, \phi, \lambda)=f_{\text {iso }}+f_{\text {vol }} K_{\mathrm{vol}}(\theta, v, \phi, \lambda)+f_{\text {geo }} K_{\text {geo }}(\theta, v, \phi, \lambda),
$$

where $\theta, v$, and $\phi$ are the solar zenith, view zenith, and relative azimuth angles, respectively. The first term $\left(f_{\text {iso }}\right)$ on the right-hand side of Equation (7) represents Lambertian reflectance. $f_{\text {vol }}$ and $f_{\text {geo }}$ are the coefficients for volumescattering $\left(K_{\mathrm{vol}}\right)$ and geometric-optical $\left(K_{\text {geo }}\right)$ kernels, respectively. These coefficients $\left(f_{\text {iso }}, f_{\text {vol }}\right.$, and $\left.f_{\text {geo }}\right)$ are available for three BRDF products, including MCD43A1, VNP43IA1, and MCD19A3, used in this study. Several major information (such as spatial and temporal resolutions) about these products is listed in Table 1, and more details (such as retrieval algorithm) can be found in the listed references. These coefficients provided by both MCD43A1 and VNP43IA1 were derived using the top-ofcanopy reflectance with varying sun-target-viewing geometries after atmospheric correction [44]. The coefficients in MCD19A3 were directly derived from top-of-atmosphere L1B reflectance using the MultiAngle Implementation of Atmospheric Correction (MAIAC) algorithm [45, 46]. Both MCD43A1 and VNP43IA1 were released at a daily interval, while MCD19A3 was released in an 8-day interval. For all three products, the BRDF parameters with best quality were used in this study according to the QA layer. The $\operatorname{Red}_{\mathrm{V}}$ $\left(\mathrm{NIR}_{\mathrm{V}}\right)$ derived from MCD43 BRDF, VNP43 BRDF, and MCD19 BRDF were denoted as MCD43 $\operatorname{Red}_{V}\left(\mathrm{NIR}_{\mathrm{V}}\right)$,
VNP43 $\operatorname{Red}_{\mathrm{V}}\left(\mathrm{NIR}_{\mathrm{V}}\right)$, and MCD19 $\operatorname{Red}_{\mathrm{V}}\left(\mathrm{NIR}_{\mathrm{V}}\right)$, respectively. In addition, the differences in band configurations between TROPOMI and MODIS/VIIRS sensors were ignored due the marginal RMSE $<0.007$ and 0.04 for red and NIR bands, respectively (Figure 3 ).

2.4. Leaf Area Index (LAI) Products. Three LAI products were used, including MODIS LAI (MCD15A2H), VIIRS LAI (VNP15A2H), and CGLS LAI (GEOV2) (see details in Table 2). MCD15A2H and VNP15A2H retrieval algorithms are based on a 3-D radiative transfer model that can simulate spectral canopy properties for each biome [47, 48]. A lookup-table technique was developed as the main method to retrieve LAI. When the main method failed, a back-up solution based on the empirical relationships between LAI and NDVI was used [48]. Note that only LAI retrievals from the main method were used in this study. CGLS LAI (version GEOV2) was derived from PROBA-V using an artificial neural network (ANN) that was trained based on MODIS/TERRA collection 5 and CYCLOPES V3.1 data $[49,50]$. The LAI values outside the expected ranges were excluded according to the quality flag (QFLAG) provided in the CGLS products. The temporal series of CGLS LAI were smoothed, with a temporal resolution of 10 days [51], and MCD15A2H and VNP15A2H were composited over 8 days [52]. The uncertainty in $i_{0}\left(\sigma_{i 0}\right)$ was calculated using the error propagation model as follows:

$$
\sigma_{i 0}=\frac{G(\theta) \times C I}{\cos \theta} \times \operatorname{EXP}\left(\frac{-G(\theta) \times \mathrm{CI} \times \mathrm{LAI}}{\cos \theta}\right) \times \sigma_{\mathrm{LAI}},
$$

where $\sigma_{\text {LAI }}$ is the retrieval uncertainty in LAI products. In this study, $\sigma_{\text {LAI }}$ was obtained from the standard deviation provided in MCD15 and VNP15 LAI products and the RMSE (root mean square error) provided in CGLS LAI product. The $i_{0}$ derived from MCD15 LAI, VNP15 LAI, and CGLS LAI were denoted as MCD15 $i_{0}$, VNP15 $i_{0}$, and CGLS $i_{0}$, respectively. All absolute uncertainties in LAI and $i_{0}$ were divided by their own values to represent the relative uncertainties (in \%) following Fang et al. [53]. 


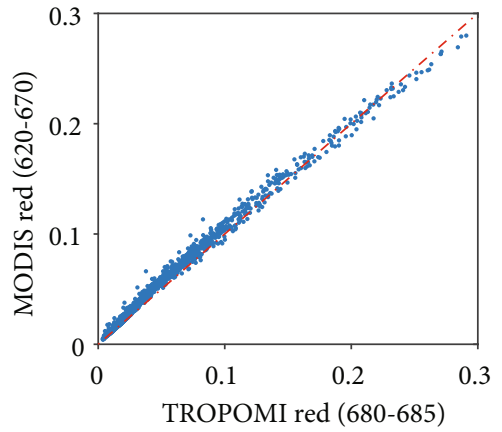

(a) RMSE $=0.0052$

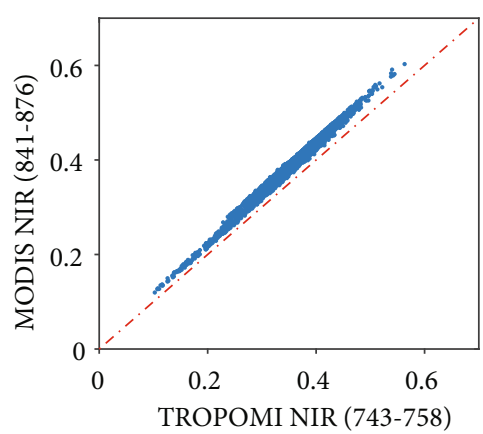

(c) RMSE $=0.0360$

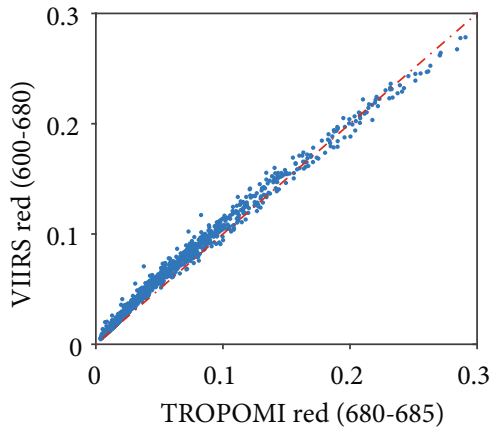

(b) RMSE $=0.0069$

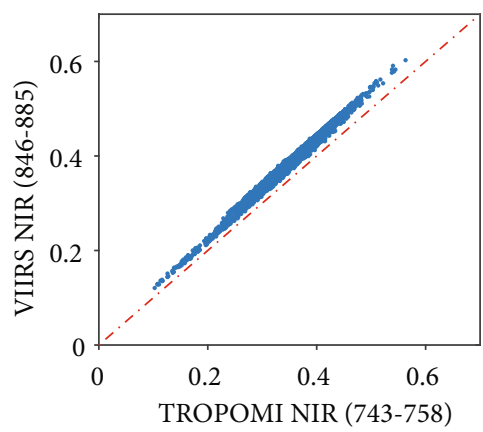

(d) RMSE $=0.0363$

Figure 3: The comparison of red and NIR reflectance from different spectral regions based on the SCOPE simulations.

TABLE 2: Information about the three LAI products used in this study.

\begin{tabular}{lccc}
\hline Short name & MCD15 & VNP15 & CGLS \\
\hline Product name & MCD15A2H & VNP15A2H & LAI_1km \\
Version & V006 & V001 & GEOV2 \\
Input data & MOD09GA, MYD09GA & VNP09GA & PROBA-V \\
Equatorial crossing time & $10: 30 \& 13: 30$ & $13: 30$ & $10: 30$ \\
Temporal coverage & $2000-$ & $2012-$ & $2000-2020$ \\
Global coverage interval & 8 -day & 8 -day & 10 -day \\
Spatial resolution & $500 \mathrm{~m}$ & $500 \mathrm{~m}$ & $1 \mathrm{~km}$ \\
Reference & {$[47,48]$} & {$[67,75]$} & [76, 51] \\
Data source & WWW1 & WWW1 & WWW2 \\
\hline
\end{tabular}

Note: WWW1: search.earthdata.nasa.gov; WWW2: land.copernicus.eu/global/.

2.5. GPP from Tower Flux Sites. We collected GPP from 50 flux tower sites from four flux databases, including AmeriFlux (https://ameriflux.lbl.gov/), OzFlux (http://data.ozflux .org.au/portal/home), European Flux Database (https:// www.europe-fluxdata.eu/home), and ChinaFlux after checking data availability for years 2018 and 2019 and land homogeneity (Table 3 ). The standard gap-filling approach was applied to half-hour flux (such as net ecosystem $\mathrm{CO}_{2}$ exchange) and meteorological data (such as air temperature, vapor pressure deficit, and shortwave incoming radiation) [54]. Subsequently, the gap-filled data were used to calculate half-hourly GPP with the night-time partitioning procedures, in which the daytime respiration was estimated from air temperature using the model calibrated with nighttime data [55]. For each flux site, the monthly TROPOMI SIF was determined as the mean value of all cloud-free observations (cloud fraction $<0.2$ ) within a $10 \mathrm{~km}$ radius of the site location. These days with cloudy fraction $<0.2$ were denoted as clear-sky days. The half-hour GPP data on clear-sky days were averaged to monthly GPP to match with the satellite SIF. Similarly, LAI and BRDF data for each site were also aggregated to a $10 \mathrm{~km}$ radius to be consistent with SIF.

2.6. SCOPE Model Simulation. The effects of the uncertainty on $i_{0}, \operatorname{NIR}_{\mathrm{V}}$, and $\operatorname{Red}_{\mathrm{V}}$ for the performance of $\mathrm{SIF}_{\text {total }}$ in GPP estimation were first analyzed using the SCOPE model (v1.73) [27] before analyzing the satellite SIF data and in situ GPP. The SCOPE model can simulate both SIF and GPP, providing a tool to investigate the relationships between GPP and two SIF metrics $\left(\right.$ SIF $_{\text {obs }}$ and SIF $\left._{\text {total }}\right)$. We simulated 
TABle 3: Flux tower sites used in this study.

\begin{tabular}{|c|c|c|c|c|}
\hline Site ID & Lat & Lon & Vegetation type & Reference \\
\hline AU-Das & -14.1592 & 131.3881 & SAV & [77] \\
\hline AU-Dry & -15.2588 & 132.3706 & SAV & {$[78]$} \\
\hline AU-Gin & -31.3764 & 115.7139 & WSA & - \\
\hline AU-How & -12.4952 & 131.1501 & WSA & [79] \\
\hline AU-Lit & -13.1790 & 130.7945 & SAV & {$[80]$} \\
\hline AU-Lon & -23.5233 & 144.3104 & GRA & - \\
\hline AU-Rob & -17.1175 & 145.6301 & EBF & {$[80]$} \\
\hline AU-Wom & -37.4222 & 144.0944 & $\mathrm{EBF}$ & - \\
\hline CN-Aro & 38.0444 & 100.4647 & GRA & {$[81]$} \\
\hline CN-Dam & 38.8555 & 100.3722 & $\mathrm{C} 4 \mathrm{C}$ & {$[82]$} \\
\hline $\mathrm{CN}-\mathrm{Xil}$ & 43.5506 & 116.6722 & GRA & [83] \\
\hline CN-Yuc & 36.8333 & 116.5667 & C3C before June; C4C after June & {$[84]$} \\
\hline ES-Abr & 38.7018 & -6.7859 & SAV & {$[85]$} \\
\hline ES-LM1 & 39.9427 & -5.7787 & SAV & {$[86]$} \\
\hline ES-LM2 & 39.9346 & -5.7759 & SAV & {$[86]$} \\
\hline FI-Hyy & 61.8474 & 24.2948 & ENF & [87] \\
\hline FI-Var & 67.7549 & 29.6100 & ENF & - \\
\hline IT-Tor & 45.8444 & 7.5781 & GRA & [88] \\
\hline RU-Fy2 & 56.4476 & 32.9019 & ENF & [89] \\
\hline RU-Fyo & 56.4615 & 32.9221 & ENF & [89] \\
\hline US-Bi2 & 38.1090 & -121.5350 & $\mathrm{C} 4 \mathrm{C}$ & {$[90]$} \\
\hline US-Ha1 & 42.5378 & -72.1715 & DBF & [91] \\
\hline US-Ho1 & 45.2041 & -68.7402 & ENF & - \\
\hline US-MMS & 39.3232 & -86.4131 & $\mathrm{DBF}$ & - \\
\hline US-Ne1 & 41.1651 & -96.4766 & $\mathrm{C} 4 \mathrm{C}$ & [92] \\
\hline US-Ne2 & 41.1649 & -96.4701 & C3C (2018); C4C (2019) & {$[92]$} \\
\hline US-Ne3 & 41.1797 & -96.4397 & C3C (2018); C4C (2019) & {$[92]$} \\
\hline US-NR1 & 40.0329 & -105.5464 & ENF & {$[93]$} \\
\hline US-Ro4 & 44.6781 & -93.0723 & GRA & - \\
\hline US-Ro5 & 44.6910 & -93.0576 & C4C (2018); C3C (2019) & - \\
\hline US-Ro6 & 44.6946 & -93.0578 & $\mathrm{C} 3 \mathrm{C}$ & - \\
\hline US-Rpf & 65.1198 & -147.4290 & $\mathrm{DBF}$ & {$[94]$} \\
\hline US-Syv & 46.2420 & -89.3477 & MF & [95] \\
\hline US-ton & 38.4316 & -120.9660 & WSA & {$[96]$} \\
\hline US-Var & 38.4133 & -120.9507 & GRA & {$[96]$} \\
\hline US-Vcm & 35.8884 & -106.5321 & ENF & - \\
\hline US-WCr & 45.8059 & -90.0799 & $\mathrm{DBF}$ & [97] \\
\hline US-Wkg & 31.7365 & -109.9419 & GRA & [98] \\
\hline US-xAB & 45.7624 & -122.3303 & ENF & - \\
\hline US-xAE & 35.4106 & -99.0588 & GRA & - \\
\hline US-xBR & 44.0639 & -71.2873 & DBF & - \\
\hline US-xCL & 33.4012 & -97.5700 & GRA & - \\
\hline US-xDC & 47.1617 & -99.1066 & GRA & - \\
\hline US-xDL & 32.5417 & -87.8039 & $\mathrm{MF}$ & - \\
\hline US-xHA & 42.5369 & -72.1727 & $\mathrm{DBF}$ & - \\
\hline US-xKA & 39.1104 & -96.6130 & GRA & - \\
\hline US-xKZ & 39.1008 & -96.5631 & GRA & - \\
\hline
\end{tabular}


TABLE 3: Continued.

\begin{tabular}{lcccc}
\hline Site ID & Lat & Lon & Vegetation type & Reference \\
\hline US-xST & 45.5089 & -89.5864 & DBF & - \\
US-xTA & 32.9505 & -87.3933 & ENF & - \\
US-xUN & 46.2339 & -89.5373 & MF & - \\
\hline
\end{tabular}

C3C: $\mathrm{C}_{3}$ crop; C4C: $\mathrm{C}_{4}$ crop; DBF: deciduous broadleaf forest; EBF: evergreen broadleaf forest; ENF: evergreen needle leaf forest; GRA: grass; MF: mixed forest; SAV: savanna; WSA: wood savanna.

TABLE 4: The input parameters of the SCOPE model simulations.

\begin{tabular}{lcc}
\hline Parameter & Meaning & Ranges \\
\hline $\mathrm{Cab}\left(\mu \mathrm{g} / \mathrm{cm}^{2}\right)$ & Chlorophyll content & $1-80$ \\
$\mathrm{Cca}\left(\mu \mathrm{g} / \mathrm{cm}^{2}\right)$ & Carotenoid content & $1-20$ \\
$\mathrm{Cdm}\left(\mathrm{g} / \mathrm{cm}^{2}\right)$ & Dry matter content & $0.001-0.02$ \\
$\mathrm{Cw}\left(\mathrm{g} / \mathrm{cm}^{2}\right)$ & Water content & $0.004-0.04$ \\
$\mathrm{~N}$ & Leaf thickness parameters & $1-3$ \\
$\mathrm{LIDFa}, \mathrm{LIDFb}$ & Leaf inclination and variation & Planophile $(1,0)$, erectophile $(-1,0)$, Plagiophile $(0,-1)$, \\
$\mathrm{LAI}\left(\mathrm{m}^{2} / \mathrm{m}^{2}\right)$ & Leaf area index & $0.5-7$ \\
tts $\left({ }^{\circ}\right)$ & Solar zenith angle & $0-60$ \\
tto $\left({ }^{\circ}\right)$ & View zenith angle & $0-60$ \\
psi $\left(^{\circ}\right)$ & Relative azimuthal angle & $0-180$ \\
Rin $\left(\mathrm{W} / \mathrm{m}^{2}\right)$ & Incoming & $100-1000$ \\
\hline
\end{tabular}

5000 scenarios with the random combinations of biochemical, structural, and meteorological parameters listed in Table 4. To be consistent with TROPOMI SIF, the simulated

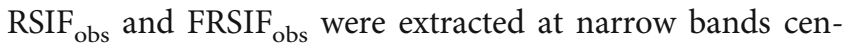
tered at $683 \mathrm{~nm}$ and $740 \mathrm{~nm}$, respectively. Different levels of random uncertainty ranging from 0 to $40 \%$ were added to $i_{0}, \mathrm{NIR}_{\mathrm{V}}$, and $\operatorname{Red}_{\mathrm{V}}$ to investigate the sensitivity of $\operatorname{SIF}_{\text {total }}$ to the uncertainty in remote sensing products. Note that the SCOPE simulations can be considered the instantaneous observations for GPP and SIF [27]. In addition, only the $\mathrm{C}_{3}$ photosynthesis pathway was considered for simplicity, because similar results can be expected between $\mathrm{C}_{3}$ and $\mathrm{C}_{4}$ photosynthesis pathways. The sun and view geometric information was represented as solar zenith angle, view zenith angle, and relative azimuthal angle. For each simulation scenario, random combinations of all parameters in their own ranges (Table 4) were generated.

\section{Results}

3.1. Sensitivity of the GPP-SIF total Relationships to Uncertainty in $i_{0}, \operatorname{Red}_{V}$, and $N I R_{V}$. The relationships of instantaneous GPP with RSIF obs $_{\text {and }}$ FRSIF obs $_{\text {based on the }}$ SCOPE simulations are shown in Figure 4(a) and 4(b), in which hyperbolic models were suitable for capturing the nonlinearity. Without considering the variation in the escape probability, RSIF $_{\text {obs }}$ was weakly and nonlinearly related to GPP $\left(R^{2}=0.38\right.$, Figure $\left.4(\mathrm{a})\right)$, and FRSIF $_{\text {obs }}$ was moderately and nonlinearly related to GPP $\left(R^{2}=0.65\right.$, Figure $4(\mathrm{~b}))$. These $R^{2}$ for $\mathrm{RSIF}_{\mathrm{obs}}$ vs. GPP and $\mathrm{FRSIF}_{\mathrm{obs}}$ vs. GPP were set as the benchmark to evaluate the usefulness of SIF $_{\text {total }}$ after considering the escape probability effect. When the uncertainties were not added into $\operatorname{Red}_{V}, \mathrm{NIR}_{\mathrm{V}}$, and $i_{0}$, both RSIF total and FRSIF total exhibited improved relationships with GPP. $R^{2}$ increased from 0.38 for GPP vs. RSI$\mathrm{F}_{\text {obs }}$ to 0.76 for GPP vs. RSIF total (Figure 4(c)), and $R^{2}$ increased from 0.65 for GPP vs. FRSIF obs to 0.79 for GPP and FRSIF total $($ Figure 4(d)). The SCOPE simulation demon-

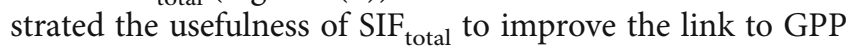
by accounting for the varying escape probability.

Figure 5 shows the 2-D distribution of $R^{2}$ for hyperbolic models between GPP and SIF total derived from $i_{0}, \operatorname{Red}_{\mathrm{V}}$, and $\mathrm{NIR}_{\mathrm{V}}$ with different levels of uncertainties. In general, $R^{2}$ decreased with the increased level of uncertainties in $i_{0}$, $\operatorname{Red}_{\mathrm{V}}$, and $\mathrm{NIR}_{\mathrm{V}}$. The black lines in Figure 5 represent the contour lines with $R^{2}$ of 0.38 for RSIF obs $_{\text {and }}$ a.65 for FRSI$\mathrm{F}_{\text {obs }}$. As compared to $\mathrm{RSIF}_{\mathrm{obs}}, \mathrm{RSIF}_{\text {total }}$ would be well related to GPP when the uncertainty in $i_{0}$ and $\operatorname{Red}_{\mathrm{V}}$ is less than $\sim 30 \%$ (Figure 5(a)). Similarly, if the uncertainty in $i_{0}$ and $\mathrm{NIR}_{\mathrm{V}}$ is less than $\sim 20 \%, \mathrm{FRSIF}_{\text {total }}$ would also be better related to GPP than FRSIF $_{\text {obs }}$ (Figure 5(b)). However, when the uncertainties in $\operatorname{Red}_{\mathrm{V}}, \mathrm{NIR}_{\mathrm{V}}$, and $i_{0}$ exceeded the uncertainty threshold ( $\sim 30 \%$ for RSIF and $20 \%$ for FRSIF), the estimated SIF $_{\text {total }}$ was too noisy and could not improve the relationships with GPP compared to SIF $_{\text {obs }}$.

3.2. Comparison of $i_{0}$, Red ${ }_{V}$, and $N I R_{V}$ among Different Products. High consistencies were found among MCD15 $i_{0}$, VNP15 $i_{0}$, and CGLS $i_{0}$ (Figure 6). The correlation between MCD15 $i_{0}$ and VNP15 $i_{0}$ was as high as 0.99 (Figure 6(a)), 


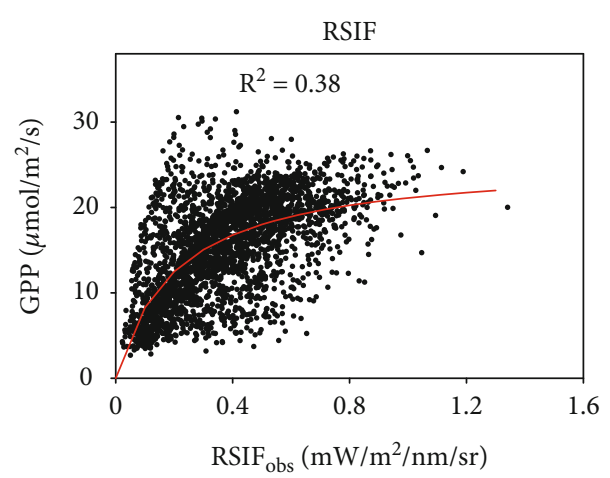

(a)

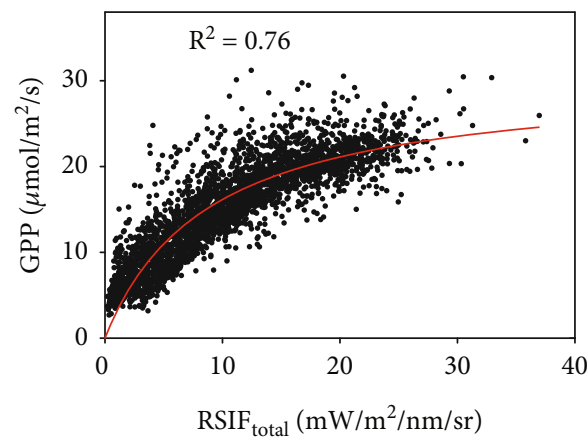

(c)

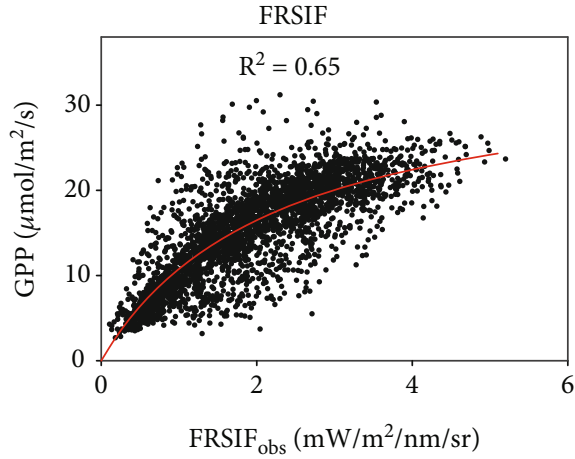

(b)

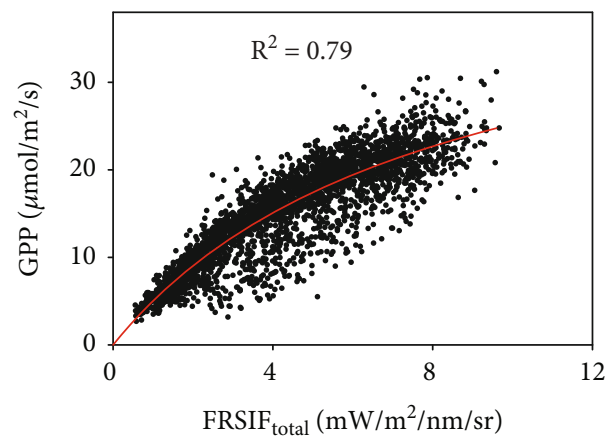

(d)

FIGURE 4: Relationships between GPP and (a) RSIF $_{\text {obs }}$, (b) FRSIF ${ }_{\text {obs }}$, (c) RSIF total, and (d) FRSIF $_{\text {total }}$ based on SCOPE model simulations.

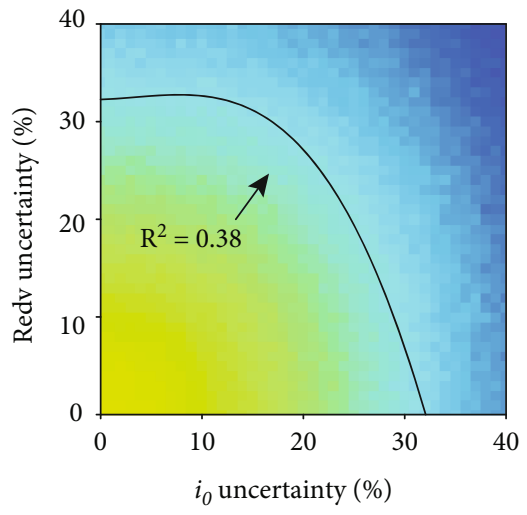

(a)

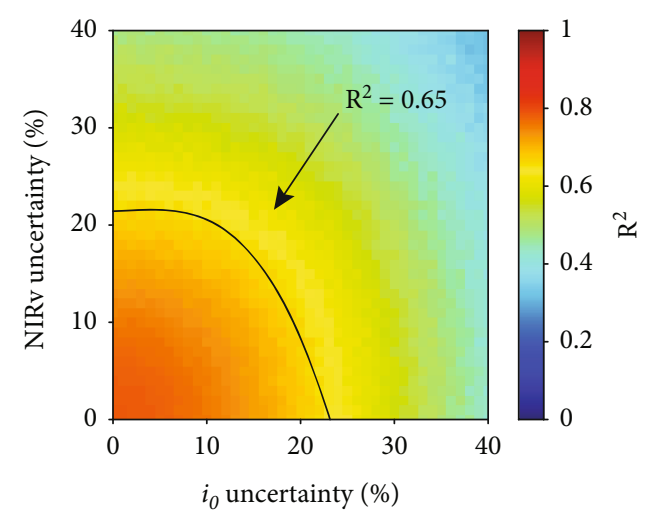

(b)

Figure 5: The coefficient of determination $\left(R^{2}\right)$ between GPP and SIF $_{\text {total }}$ calculated with $\operatorname{Red}_{\mathrm{V}}$, NIR $\mathrm{V}_{\mathrm{V}}$, and $i_{0}$ under different levels of uncertainty. (a) RSIF total calculated with $\operatorname{Red}_{\mathrm{V}}$ and $i_{0}$ and (b) FRSIF total calculated with $\mathrm{NIR}_{\mathrm{V}}$ and $i_{0}$. $R^{2}$ between GPP and SIF obs was indicated as a black line for benchmark.

which was expected due to their similar retrieval algorithms for LAI. In contrast, CGLS $i_{0}$ exhibited good but weaker relationships with MCD15 $i_{0}\left(R^{2}=0.92\right.$ in Figure 6(b)) and VNP15 $i_{0}\left(R^{2}=0.90\right.$ in Figure 6(c)). In addition, three LAI products showed similar levels of uncertainty after normalizing uncertainties with each LAI itself (Figures 7(a)-7(c)). The uncertainties in percentage were estimated as $23.51 \%$, $22.95 \%$, and $22.86 \%$ for MCD15 LAI, VNP15 LAI, and CGLS LAI, respectively (Figures $7(\mathrm{a})-7(\mathrm{c})$ ). Therefore, $i_{0}$ derived from these LAI products also showed similar levels of uncertainty in the range of $16.27 \%-17.10 \%$ (Figures $7(\mathrm{~d})-7(\mathrm{f})$ ). Fortunately, the uncertainty levels of $i_{0}$ derived from all three satellite LAI products were less than the thresholds ( $30 \%$ for RSIF and $20 \%$ for FRSIF) determined by the SCOPE simulations (Figure 5).

Moderately to highly strong relationships were found among $\operatorname{Red}_{\mathrm{V}}$ derived from three BRDF products with $R^{2}$ in the range of 0.82 to 0.93 , and only a few data points diverged from the regression line (Figures $8(a)-8(c)$ ). This indicated that these BRDF products estimated consistent vegetation 


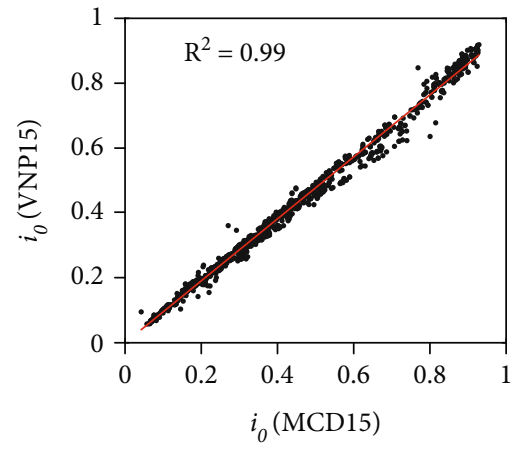

(a)

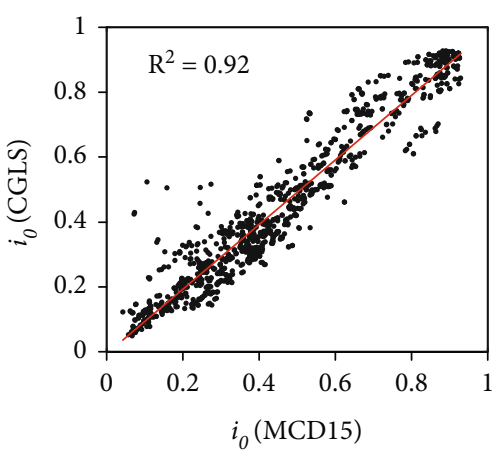

(b)

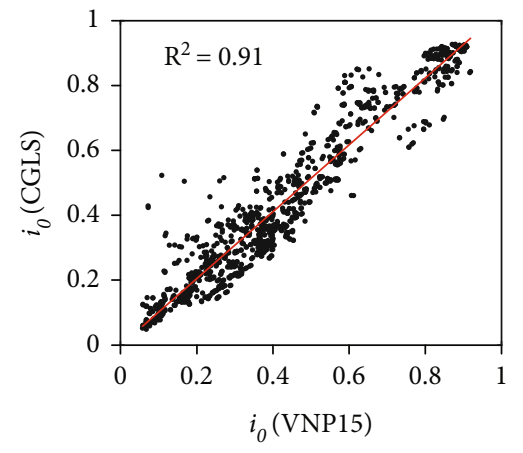

(c)

Figure 6: Comparison of $i_{0}$ derived from three LAI products: (a) MCD15 $i_{0}$ vs. VNP15 $i_{0}$, (b) MCD15 $i_{0}$ vs. CGLS $i_{0}$, and (c) VNP15 $i_{0}$ vs. CGLS $i_{0}$. LAI data were picked within a radius of $10 \mathrm{~km}$ around flux sites during 2018-2019.

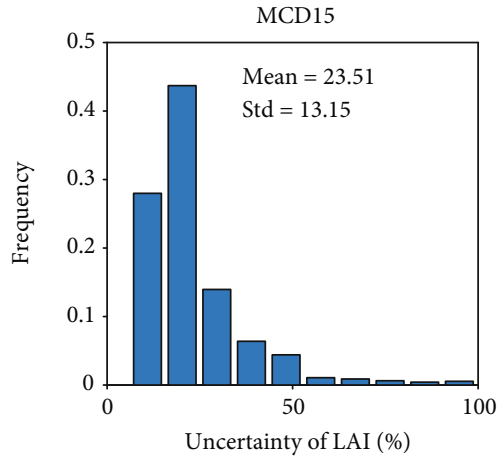

(a)

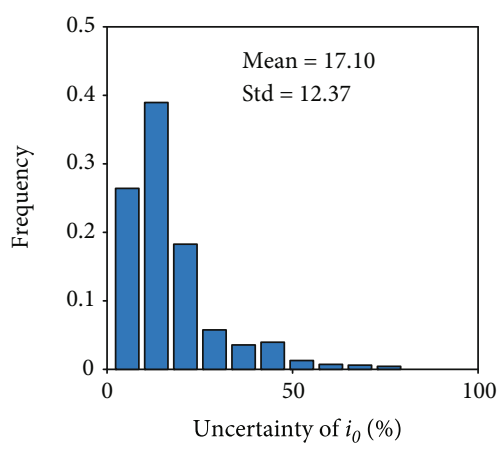

(d)

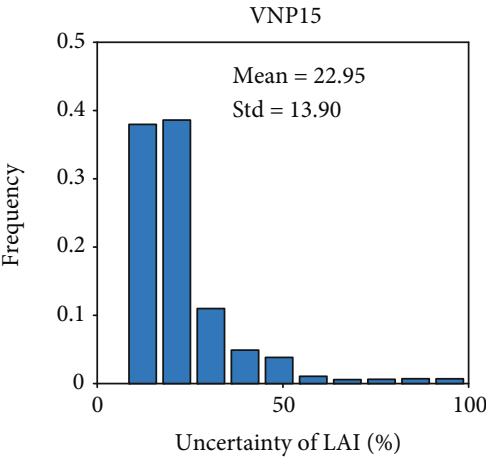

(b)

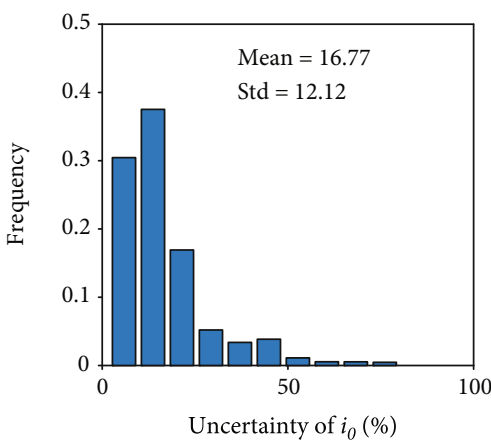

(e)

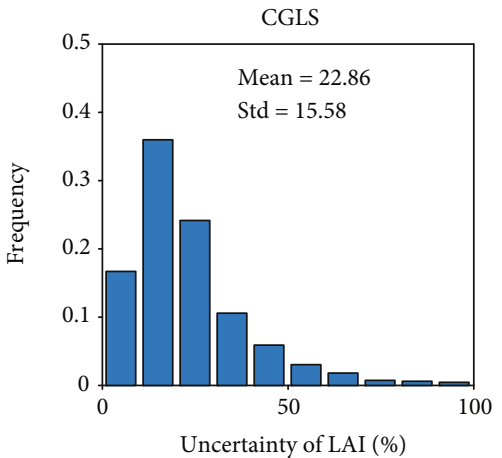

(c)

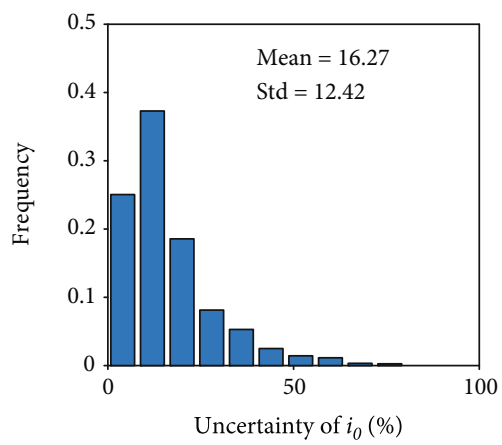

(f)

Figure 7: Statistics of uncertainties (\%) in LAI (first row) and $i_{0}$ (second row) from three LAI products: MCD15 (first column), VNP15 (second column), and CGLS (third column). For comparison purpose, uncertainties in LAI and $i_{0}$ were normalized by LAI and $i_{0}$, respectively, and shown in percentage (\%).

reflectance in the red band overall. Compared to the red band, stronger and more consistent relationships were found for $\mathrm{NIR}_{\mathrm{V}}$, with $R^{2}>0.95$ (Figures $8(\mathrm{~d})-8(\mathrm{f})$ ). Since these $\mathrm{BRDF}$ products did not provide uncertainty information, the uncertainty of $\operatorname{Red}_{\mathrm{V}}$ and $\mathrm{NIR}_{\mathrm{V}}$ was not compared in this study.

3.3. Tower Flux GPP against TROPOMI RSIF and FRSIF. The scatter plots of GPP against $\mathrm{RSIF}_{\text {obs }}$ and FRSIF $_{\text {obs }}$ from TROPOMI are shown in Figure 9, in which $\mathrm{C}_{3}$ and $\mathrm{C}_{4}$ plants were separated due to their distinct photosynthe- sis pathways. The nonlinear model was used in the instantaneous GPP and SIF based on the SCOPE simulations, but linear models were efficient to capture the relationships between monthly GPP and SIF for both $\mathrm{C}_{3}$ and $\mathrm{C}_{4}$ plants. In general, FRSIF $_{\text {obs }}$ showed better relationships with GPP than RSIF $_{\text {obs }}$ regardless of $\mathrm{C}_{3}$ and $\mathrm{C}_{4}$ plants, which was consistent with the SCOPE simulations. In addition, higher $R^{2}$ and slope of linear model were observed for $\mathrm{C}_{4}$ plants than that for $\mathrm{C}_{3}$ plants. This higher slope for $\mathrm{C}_{4}$ plants is attributed to the lower photorespiration and higher efficiency of photosynthesis in plants with 


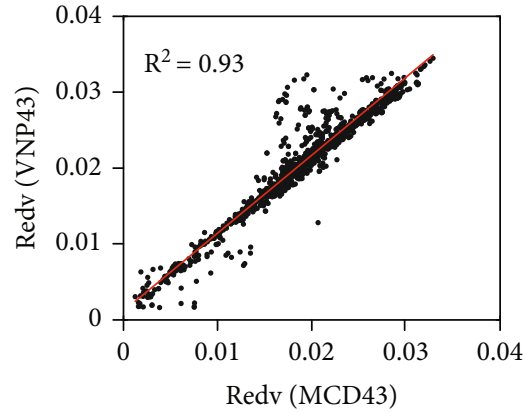

(a)

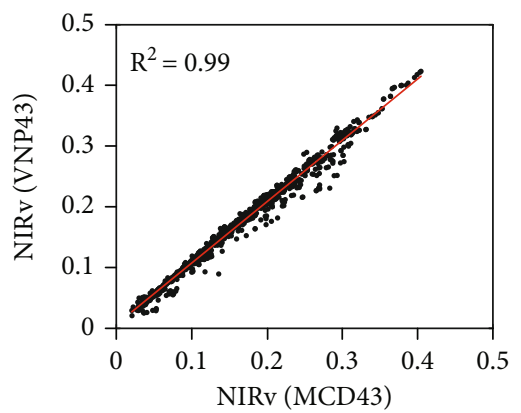

(d)

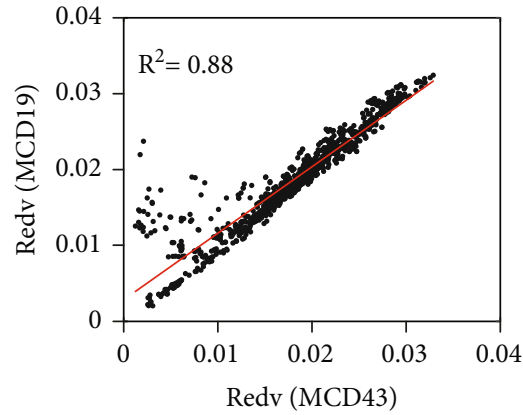

(b)

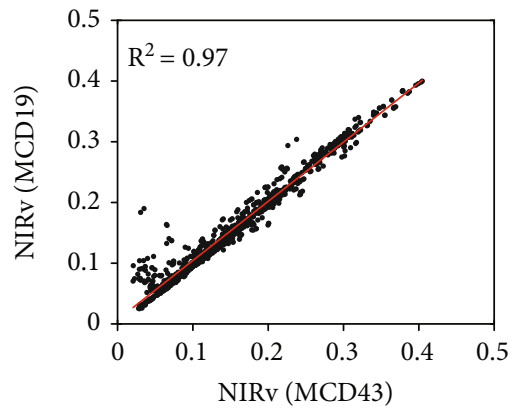

(e)

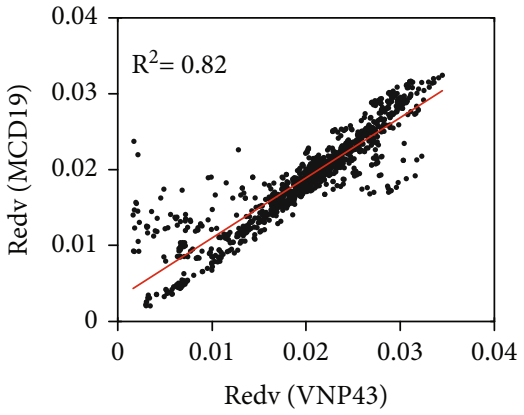

(c)

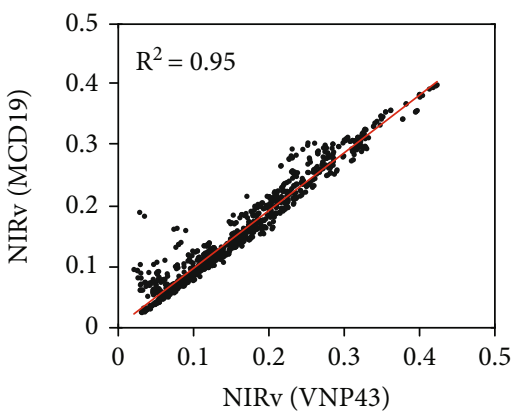

(f)

FIGURE 8: Comparison of $\operatorname{Red}_{\mathrm{V}}$ (first row) and $\mathrm{NIR}_{\mathrm{V}}$ (second row) derived from three BRDF products: MCD43, VNP43, and MCD19. Red and $\mathrm{NIR}_{\mathrm{V}}$ were picked within a radius of $10 \mathrm{~km}$ around flux sites during 2018-2019.

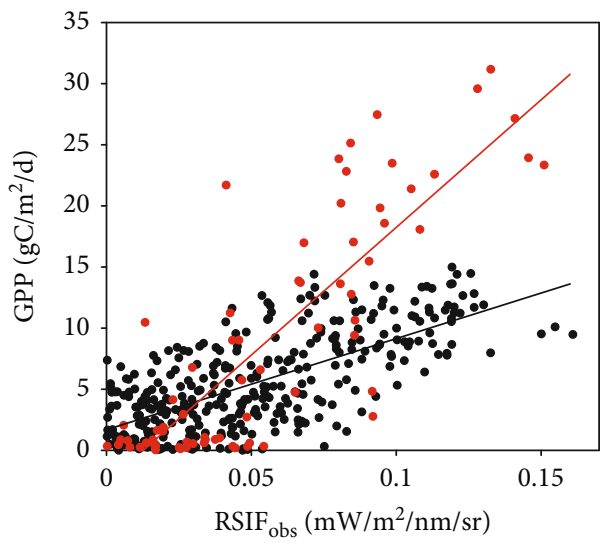

- C3: 0.49

- C4: 0.71

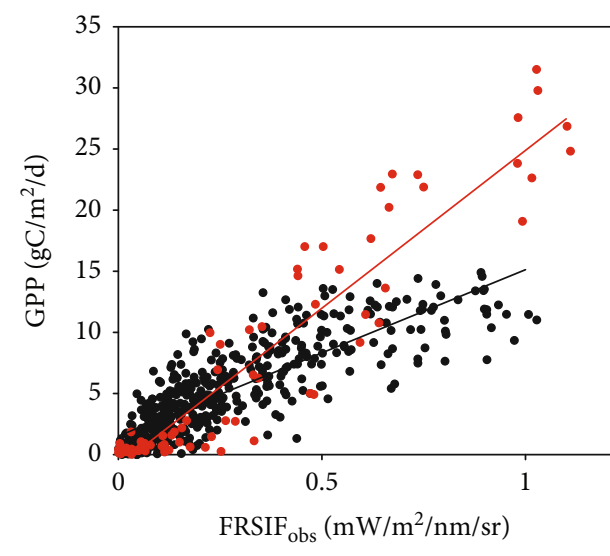

- C3: 0.70

- C4: 0.88

(a)

(b)

FIGURE 9: Relationships between tower flux monthly averaged GPP and (a) RSIF obs (C3: $y=74.53 x+1.69 ;$ C4: $y=208.79 x-2.64)$ and (b) FRSIF $_{\text {obs }}(\mathrm{C} 3: y=13.60 x+1.52$; C4: $y=25.82 x-0.93)$. For simplicity, these sites were classified into two types: $\mathrm{C}_{3}$ and $\mathrm{C}_{4}$ plants, with following number indicating the coefficient of determination $\left(R^{2}\right)$. All regression models are statistically significant $(p$ value $<0.001)$.

$\mathrm{C}_{4}$ metabolism than $\mathrm{C}_{3}$ plants $[56,57]$. We also observed an interesting phenomenon that the intercept was positive and negative for $\mathrm{C}_{3}$ and $\mathrm{C}_{4}$ plants, respectively. Theoretically, both SIF and GPP are from APAR, so the intercept should be zero (when APAR is zero) under natural conditions. The nonzero intercept reported here could be caused by the regression model uncertainties, the bias in satellite SIF retrievals, the bias in flux tower GPP partition, and the environmental stress.
After accounting for the difference in escape probability, the relationships of GPP with RSIF $_{\text {total }}$ and FRSIF total $_{\text {are }}$ presented in Figures 10 and 11. The poorest relationship was obtained between GPP and RSIF $_{\text {total }}$ in $\mathrm{C}_{3}$ plants with $R^{2}$ from 0.55 to 0.57 (Figure 10), which was still higher than the $R^{2}$ between GPP and $\operatorname{SIF}_{\text {obs }}\left(R^{2}=0.49\right.$ in Figure 9(a)). Subsequently, $R^{2}$ between GPP and FRSIF $_{\text {total }}$ in $\mathrm{C}_{3}$ plants ranged between 0.72 and 0.77 (Figure 11), which outperformed the relationship between GPP and FRSIF $_{\text {obs }}$ 


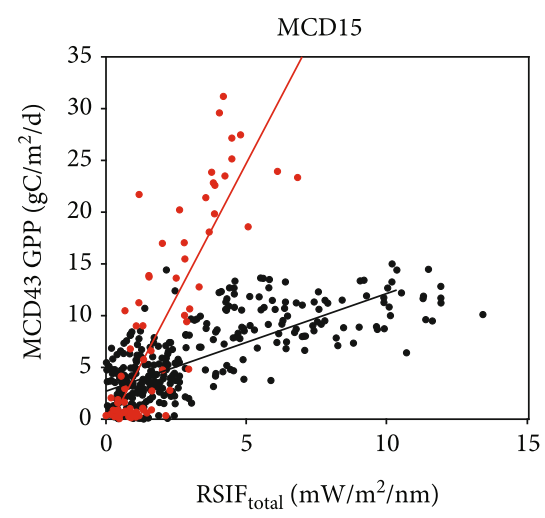

- C3: 0.55

- C4: 0.72

(a)

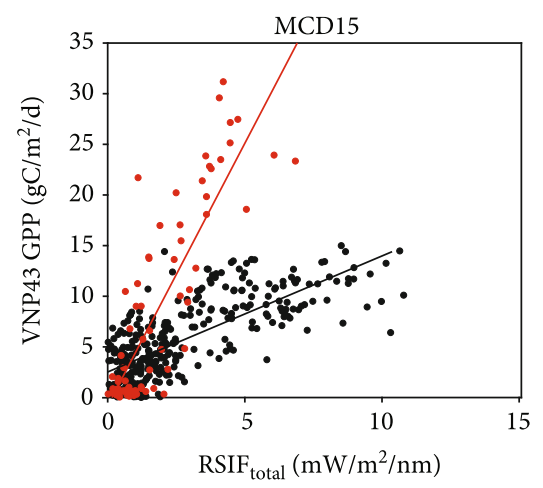

- C3: 0.55

- C4: 0.72

(d)

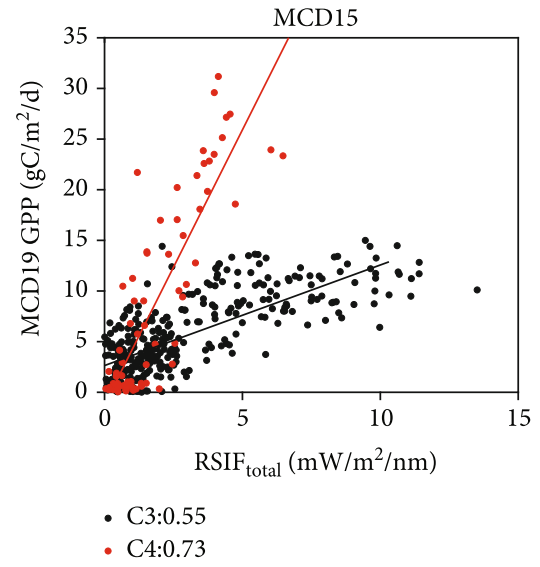

(g)

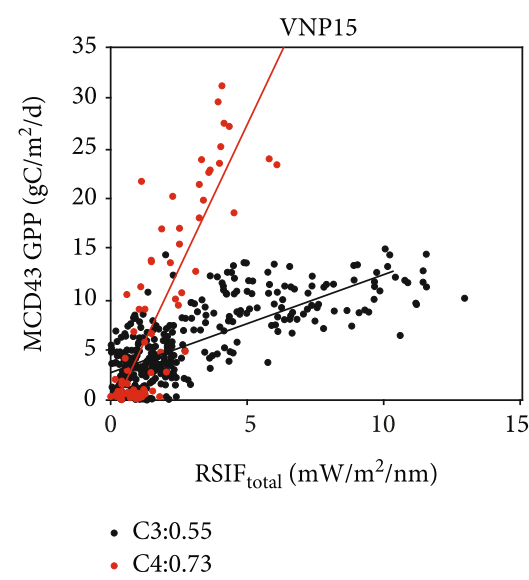

(b)

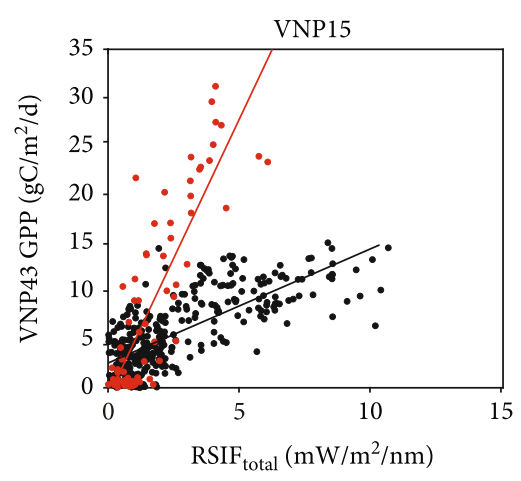

- C3: 0.55

- C4: 0.73

(e)

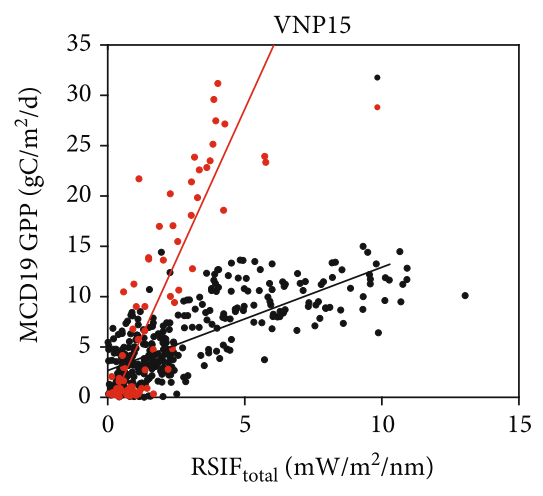

- C3: 0.55

- C4: 0.75

(h)

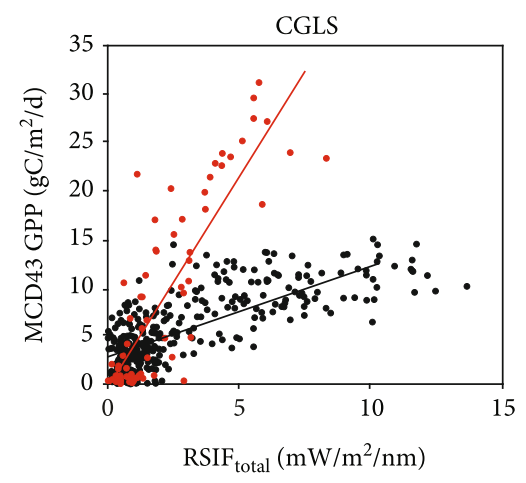

- C3: 0.57

- C4: 0.73

(c)

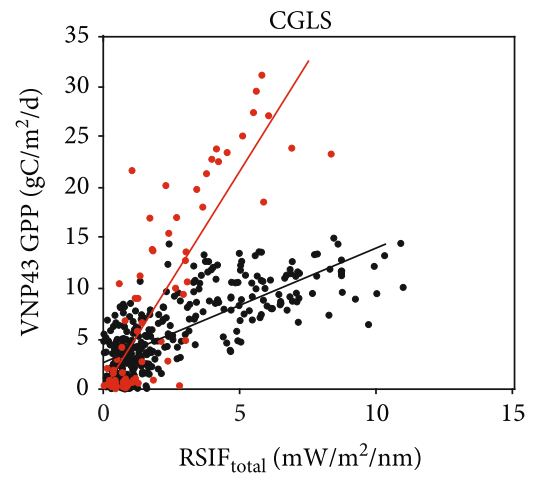

- C3: 0.57

- C4: 0.72

(f)

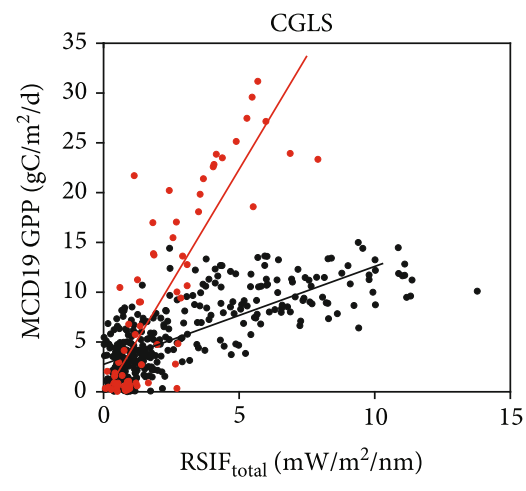

- C3: 0.57

- C4: 0.74

(i)

FIGURE 10: Relationships between tower-based GPP and TROPOMI RSIF total $_{\text {calculated with different combinations of Red }}{\text { and } i_{0} \text {. Red }}_{\mathrm{V}}$ was calculated with MCD43 (first row), VNP43 (second row), and MCD19 (third row). $i_{0}$ was calculated with MCD15 (first column), VNP15 (second column), and CGLS (third column). For simplicity, these sites were classified into two types: $\mathrm{C}_{3}$ and $\mathrm{C}_{4}$ plants, with following number indicating $R^{2}$. All regression models are statistically significant ( $p$ value $\left.<0.001\right)$.

$\left(R^{2}=0.70\right.$ in Figure 9(b)). As for $\mathrm{C}_{4}$ plants, $\mathrm{RSIF}_{\text {total }}$ also improved the relationships with GPP from RSIF $_{\text {obs }}$

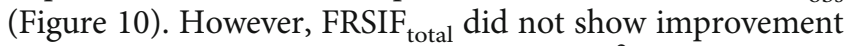
in $R^{2}$ for $\mathrm{C}_{4}$ plants (Figure 11 ), since the $\mathrm{R}^{2}$ between FRSI$\mathrm{F}_{\text {obs }}$ and GPP has reached to 0.88 (Figure 9(b)). Although there was no clear difference in $R^{2}$ obtained by different combinations of $i_{0}$ and $\operatorname{Red}_{\mathrm{V}}$ or $\mathrm{NIR}_{\mathrm{V}}$, we observed slightly higher $R^{2}$ obtained by MCD19 $\operatorname{Red}_{\mathrm{V}}$ and $\mathrm{NIR}_{\mathrm{V}}$ than those by MCD43 and VNP43 in terms of the relationship between GPP and FRSIF total . 


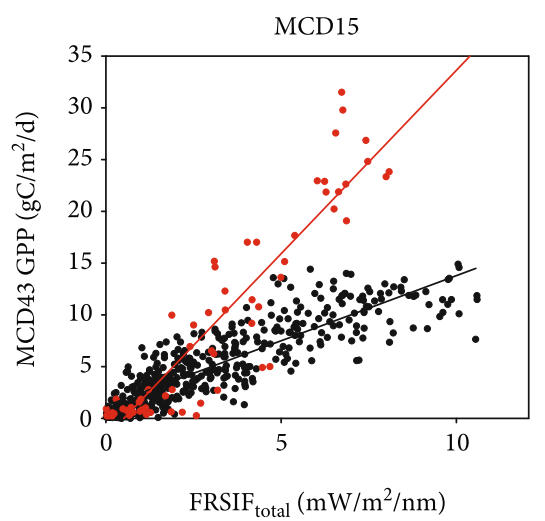

- C3: 0.75

- C4: 0.86

(a)

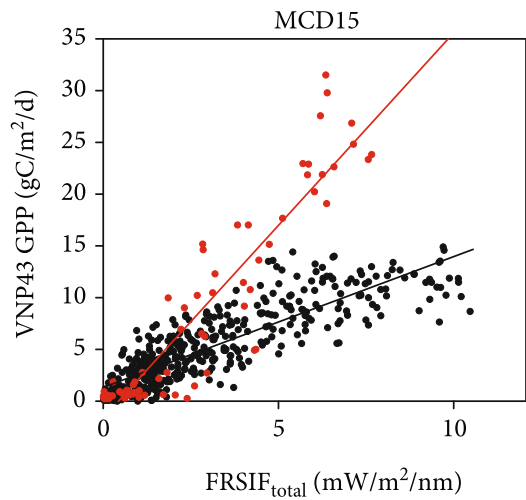

- C3: 0.75

- C4: 0.86

(d)

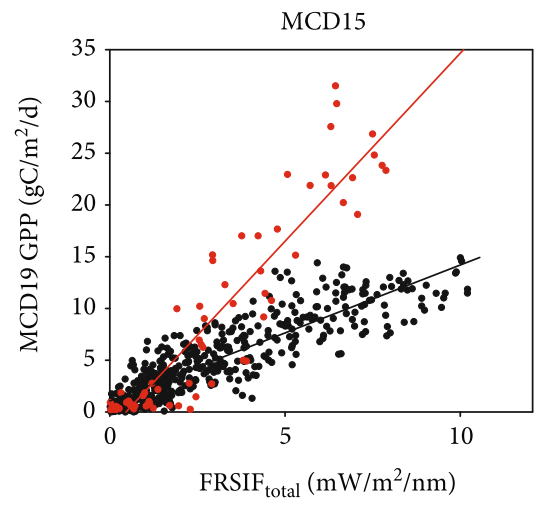

- C3: 0.77

- C4: 0.86

(g)

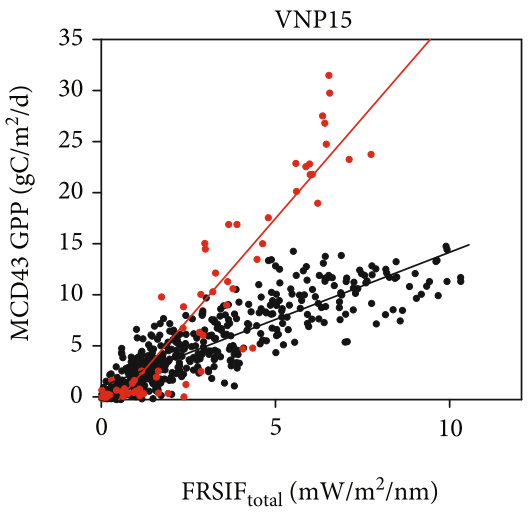

- C3: 0.75

- C4: 0.87

(b)

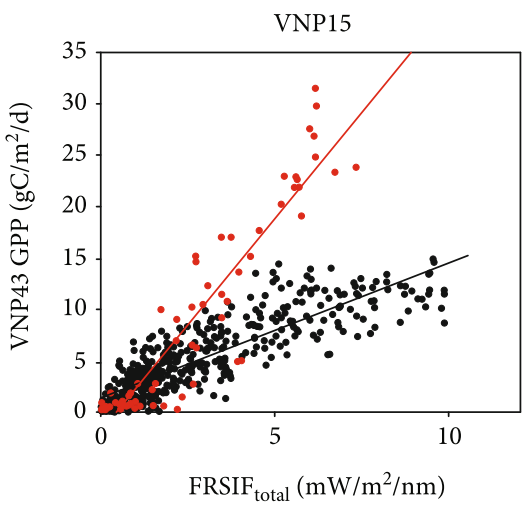

- C3: 0.74

- C4: 0.87

(e)

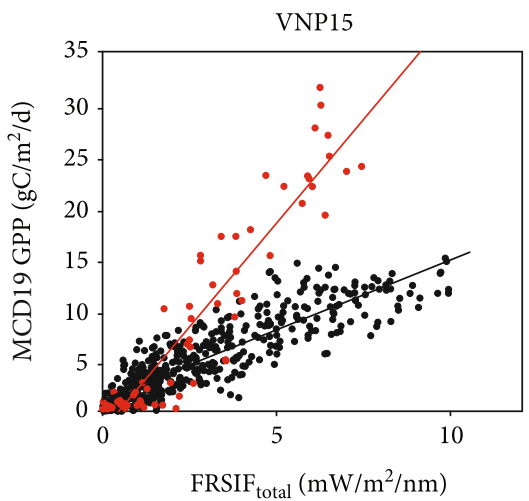

- C3: 0.77

- C4: 0.88

(h)

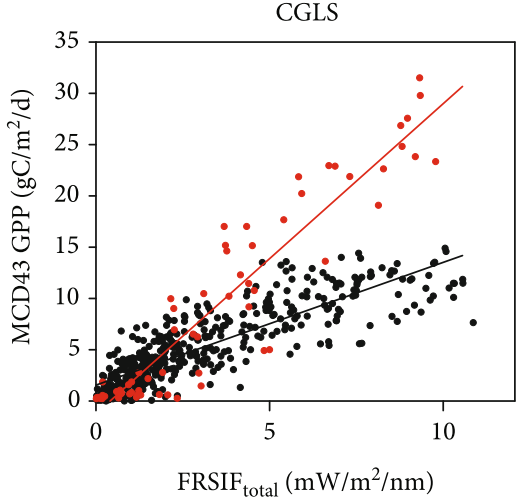

- C3:0.73

- $\mathrm{C} 4: 0.88$

(c)

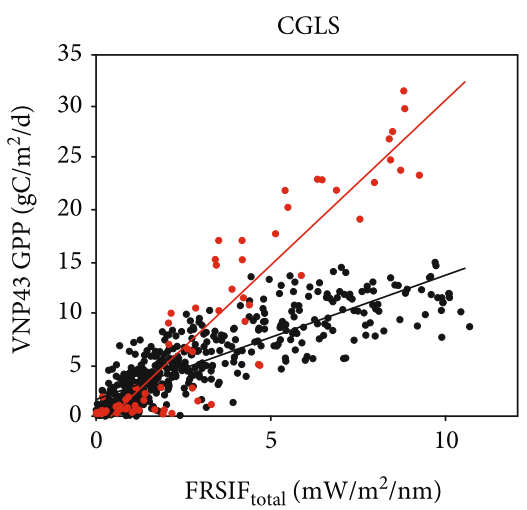

- C3: 0.72

- C4: 0.87

(f)

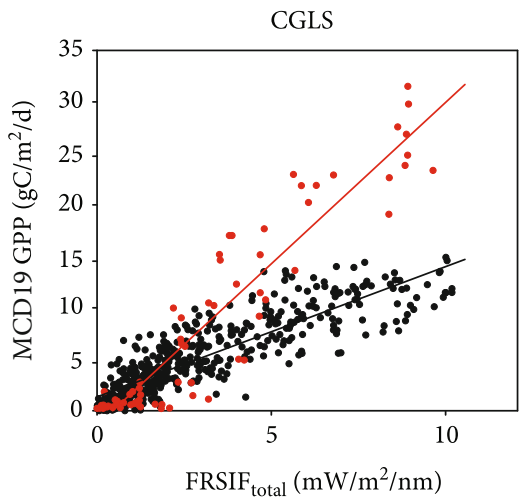

- C3: 0.76

- C4: 0.88

(i)

FIGURE 11: Relationships between tower-based GPP and TROPOMI FRSIF total calculated with different combinations of NIR V $_{\mathrm{V}}$ and $i_{0}$. NIR $\mathrm{V}_{\mathrm{V}}$ was calculated with MCD43 (first row), VNP43 (second row), and MCD19 (third row). $i_{0}$ was calculated with MCD15 (first column), VNP15 (second column), and CGLS (third column). For simplicity, these sites were classified into two types: $\mathrm{C}_{3}$ and $\mathrm{C}_{4}$ plants, with following number indicating $R^{2}$. All regression models are statistically significant ( $p$ value $<0.001$ ).

The escape probability of SIF (fesc) estimated with Equation (5) is also compared with that from the SCOPE simulations (Figure 12). For RSIF at $685 \mathrm{~nm}$, fesc calcu- lated with $\operatorname{Red}_{\mathrm{V}}$ and $i_{0}$ from different combinations of BRDF and LAI products was clearly higher than that from the SCOPE simulations. Therefore, $\mathrm{RSIF}_{\text {total }}\left(=\mathrm{RSIF}_{\text {obs }} / \mathrm{fesc}\right)$ 


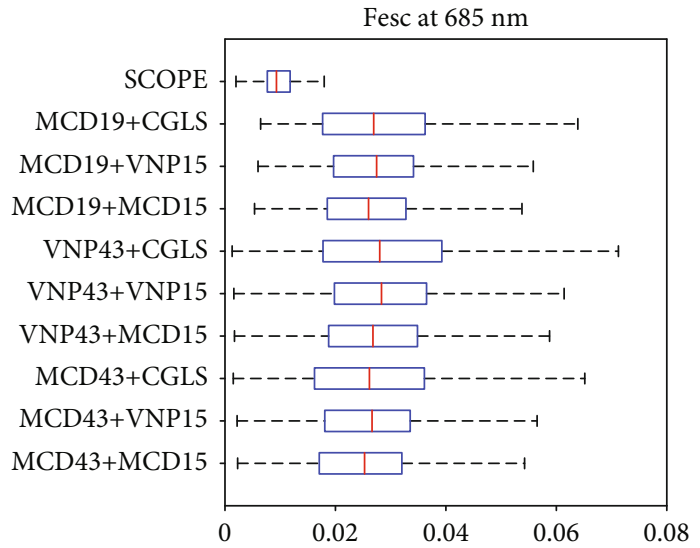

(a)

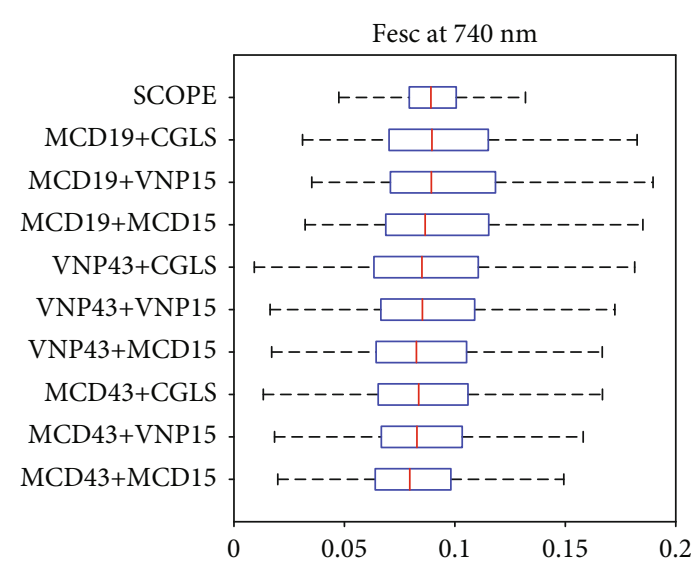

(b)

FIGURE 12: The boxplots of escape probability (fesc) of SIF at (a) $685 \mathrm{~nm}$ and (b) $740 \mathrm{~nm}$ obtained from SCOPE simulations or calculated with satellite $\operatorname{Red}_{\mathrm{V}} / \mathrm{NIR}_{\mathrm{V}}$ and $i_{0}$ products.

was underestimated in this study. A further work is still required to reduce the underestimation of $\mathrm{RSIF}_{\text {total }}$. In contrast, fesc at $740 \mathrm{~nm}$ from SCOPE simulations was better consistent with that calculated with $\mathrm{NIR}_{\mathrm{V}}$ and $i_{0}$, demonstrating the success of $\mathrm{NIR}_{\mathrm{V}}+i_{0}$ in calculating fesc at $740 \mathrm{~nm}$.

\section{Discussion}

4.1. Comparison between the SCOPE Simulation and

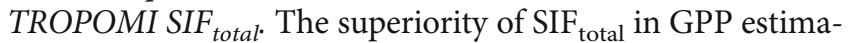
tion has been shown by recent studies [20, 23, 24]. However, the sensitivity of SIF total to uncertainty in $i_{0}, \mathrm{NIR}_{\mathrm{V}}$, and $\operatorname{Red}_{\mathrm{V}}$ has not been well understood. Based on the SCOPE simulations, the improvement in $R^{2}\left(\Delta R^{2}\right)$ can reach up to 0.38 and 0.14 for $\mathrm{RSIF}_{\text {total }}$ and FRSIF total , respectively, when no uncertainty existing in $i_{0}, \mathrm{NIR}_{\mathrm{V}}$, and $\operatorname{Red}_{\mathrm{V}}$ (Figure 4). However, the differences in $R^{2}$ tend to decrease with the increasing level of uncertainty in $i_{0}, \mathrm{NIR}_{\mathrm{V}}$, and $\operatorname{Red}_{\mathrm{V}}$ as shown in Figure 5, revealing the adverse effect of uncertainty on the relationships between GPP and $\mathrm{SIF}_{\text {total }}$. Since the uncertainty in satellite data is unavailable, $\Delta R^{2}$ for actual scenarios is likely to be less than the maximum values used in this study. For example, the actual $\Delta R^{2}$ only ranges between 0.02 (2.86\%) and $0.07(10.00 \%)$ for TROPOMI FRSIF total in $\mathrm{C}_{3}$ plants (Figure 11), which is close to the reported $\Delta R^{2}$ $(0.04,5.40 \%)$ obtained by OCO-2 FRSIF total [26]. The lower $\Delta R^{2}$ in actual scenarios is attributed to the uncertainty in $i_{0}$, $\mathrm{NIR}_{\mathrm{V}}$, and $\operatorname{Red}_{\mathrm{V}}$. The uncertainties from clumping index, Gfunction, and leaf albedo can also contribute to the lower $\Delta R^{2}$, although LAI and BRDF products are the main source of the uncertainties in SIF $_{\text {total }}$. The comparison between simulation and measurement promotes our understanding of the use of $\mathrm{SIF}_{\text {total }}$. Furthermore, this study discusses the potential uncertainty in LAI and BRDF products as below.

4.2. Impacts of Different Satellite LAI and BRDF Products on the Estimation of SIF total. Numerous studies have intercompared existing LAI products from regional to global scales in terms of spatiotemporal consistency and reported many difference among these products [58-68]. These inherent uncertainties in LAI products result from both retrieval algorithms and input data [48]. For example, to improve the inversion efficiency for MCD15 and VNP15, several biome-specific variables (e.g., canopy structure, leaf type, and soil brightness) are defined beforehand in the inversion process. As a result, the biome-specific assignments could result in uncertainty for LAI retrievals for mixed or misclassified pixels [48]. In addition, the uncertainty in atmosphere parameters could propagate into the atmospheric correction process [69], bringing also uncertainty to reflectance and hence LAI retrievals.

For most studies, CGLS product shows better accuracy as compared to MCD15 and VNP15. For example, Brown et al. [58] reported the better agreements between reference LAI and CGLS LAI than MCD15 and VNP15 LAI. However, this study observes consistent relationships among MCD15, VNP15, and CGLS $i_{0}$ with $R^{2}$ ranging from 0.90 to 0.99 (Figure 6$)$ and similar uncertainty level $(\sim 17 \%)$ in $i_{0}$ (Figure 7). As expected, improved estimation of GPP from SIF $_{\text {total }}$ is available if uncertainty in $i_{0}$ is further reduced. This can be obtained by new satellite sensors with improved spectral and spatial resolutions and more accurate retrieval algorithm, such as ESA's forthcoming FLuorescence EXplorer (FLEX) mission in tandem with Sentinel-3 [70]. Since $i_{0}$ and fraction of absorbed photosynthetically active radiation (FAPAR) are highly related [25], SIF total calculated with FPAR also exhibits similar results as compared SIF total calculated with $i_{0}$ (results not shown).

Several studies also reported the high consistency between MCD43 and VNP43 NDVI [71] and MCD43 and MCD19 NIR [72], which supports the high consistency in $\mathrm{NIR}_{\mathrm{V}}$ (the product of NDVI and NIR reflectance) among MCD43, VNP43, and MCD19 (Figure 8). Therefore, marginal differences are expected in relationship between GPP and $\operatorname{SIF}_{\text {total }}$ calculated from different $\operatorname{Red}_{\mathrm{V}}$ and $\mathrm{NIR}_{\mathrm{V}}$ (Figures 10 and 11). In terms of FRSIF total $_{\text {, the slightly higher }}$ $R^{2}$ for MCD19 than those for MCD43 and VNP43 could be attributed to the advantage of MAIAC algorithm adopted by 
MCD19. In addition, MODIS is onboard two satellites (Terra and Aqua) with two equator local crossing times of 10:30 and 13:30, and VIIRS is only onboard one satellite (Suomi-NPP) with an equator local crossing time of 13:30; the former could provide more angular samplings and full inversion for BRDF parameters than the latter [73]. However, the equator local crossing time for VIIRS is consistent with that for TROPOMI SIF, which should be more suitable for TROPOMI SIF than MCD43 and MCD19. With the additional VIIRS launched in 2017 and to be launched in the future as part of the JPSS program, an increased pixel number of full inversions will be available to generate the VNP43 product. As a result, reducing uncertainty in VNP43 could improve the calculation of SIF $_{\text {total }}$ and the estimation of GPP.

\section{Conclusions}

Previous studies have shown that SIF $_{\text {total }}$ was more useful for GPP estimation than SIF obs across multiple scales. However, the advantage of SIF $_{\text {total }}$ in improving GPP estimation could be masked by the uncertainty in the derivation of $i_{0}, \mathrm{NIR}_{\mathrm{V}}$, and $\operatorname{Red}_{\mathrm{V}}$, which were required by the calculation of $\operatorname{SIF}_{\text {total }}$. In this study, we first investigated the effect of the uncertainty in $i_{0}, \operatorname{Red}_{\mathrm{V}}$, and $\mathrm{NIR}_{\mathrm{V}}$ on the calculation of $\operatorname{SIF}_{\text {total }}$ and the relationships between SIF total and GPP based on the SCOPE model simulations. As a result, $\mathrm{SIF}_{\text {total }}$ performed better than SIF $_{\text {obs }}$ for both red and far-red bands in capturing the link with GPP. The improvement in $R^{2}\left(\Delta R^{2}\right)$ for SIF $_{\text {total }}$ and GPP relationships was 0.38 and 0.14 for RSIFtotal and FRSIF $F_{\text {total }}$ from RSIF obs and FRSIF ${ }_{\text {obs }}$, respectively. With the increasing uncertainty in $i_{0}, \mathrm{NIR}_{\mathrm{V}}$, and $\operatorname{Red}_{\mathrm{V}}$, RSIFtotal and FRSIF $_{\text {total }}$ showed degraded relationships with GPP. Furthermore, $\Delta R^{2}$ decreased to zero when the uncertainty levels were higher than $\sim 30 \%$ in $i_{0}$ and $\operatorname{Red}_{\mathrm{V}}$ (for estimation of $\mathrm{RSIF}_{\text {total }}$ ) and $\sim 20 \%$ in $i_{0}$ and $\mathrm{NIR}_{\mathrm{V}}$ (for estimation of FRSIF $_{\text {total }}$ ) based on the SCOPE model simulation. Then, this study calculated RSIF total and FRSIF total $_{\text {from TROPOMI }}$ RSIF $_{\text {obs }}$ and FRSIF ${ }_{\text {obs }}$ with different combinations of $i_{0}$ (from MCD15, VNP15, and CGLS LAI) and $\operatorname{Red}_{\mathrm{V}}$ and $\mathrm{NIR}_{\mathrm{V}}$ (from MCD43, MCD19, and VNP43). In general, TROPOMI RSIFtotal and FRSIF total exhibited better relationships with flux tower GPP than RSIF ${ }_{\text {obs }}$ and FRSIF obs. $_{\text {. Due to the compara- }}$ ble uncertainty levels among these different satellite products (such as LAI), the estimation of SIF $_{\text {total }}$ was less sensitive to the choice of satellite products. Our results based on SCOPE simulations and TROPOMI data contribute to our understanding of the estimation of $\mathrm{SIF}_{\text {total }}$ using current satellite products, which would advance the use of satellite SIF data for global terrestrial GPP estimation.

\section{Data Availability}

TROPOMI SIF was downloaded at ftp://fluo.gps.caltech .edu/data/tropomi/. MODIS and VIIRS series data were downloaded at https://search.earthdata.nasa.gov/search. Flux data were downloaded from AmeriFlux (https:// ameriflux.lbl.gov/), OzFlux (http://data.ozflux.org.au/portal/ home), European Flux Database (https://www.europe- fluxdata.eu/home), and Heihe Plan Science Data Center (http://www.heihedata.org).

\section{Conflicts of Interest}

The authors declare that there is no conflict of interest regarding the publication of this article.

\section{Authors' Contributions}

Z.Z. proposed the method and wrote and revised the paper with Y.Z., J.M.C., W.J., M.M., and T.S.E. Z.Z., Y.Z., J.M.C., and W.J. conceptualized the method. M.M. and T.S.E. contributed to the field measurement.

\section{Acknowledgments}

This research was supported by the National Key R\&D Program of China (2016YFA0600202), the General Program of NSFC (42071388), and the fellowship of China Postdoctoral Science Foundation (2021M691491). This work used eddy covariance data acquired and shared by the FLUXNET community, including the following networks: AmeriFlux, CarboEuropeIP, ChinaFlux, and OzFlux-TERN. The data from $\mathrm{CN}$-Aro and CN-Dam was provided by "Heihe Plan Science Data Center, National Natural Science Foundation of China" (http://www.heihedata.org). We also acknowledge Dr. Philipp Köhler and Prof. Christian Frankenberg for providing original TROPOMI SIF (ftp://fluo.gps.caltech.edu/ data/tropomi/). The authors are thankful to the science team members who produce and manage MODIS, VIIRS, and CGLS products. We would like to thank Prof. Christiaan van der Tol for making the SCOPE model publicly available.

\section{References}

[1] C. Frankenberg, J. B. Fisher, J. Worden et al., "New global observations of the terrestrial carbon cycle from GOSAT: patterns of plant fluorescence with gross primary productivity," Geophysical Research Letters, vol. 38, no. 17, pp. 351-365, 2011.

[2] L. Guanter, Y. Zhang, M. Jung et al., "Global and time-resolved monitoring of crop photosynthesis with chlorophyll fluorescence," Proceedings of the National Academy of Sciences of the United States of America, vol. 111, no. 14, pp. E1327E1333, 2014.

[3] Y. Sun, C. Frankenberg, J. D. Wood et al., "OCO-2 advances photosynthesis observation from space via solar-induced chlorophyll fluorescence," Science, vol. 358, no. 6360, p. eaam5747, 2017.

[4] S. du, L. Liu, X. Liu et al., "Retrieval of global terrestrial solarinduced chlorophyll fluorescence from TanSat satellite," Science Bulletin, vol. 63, no. 22, pp. 1502-1512, 2018.

[5] C. Frankenberg, A. Butz, and G. C. Toon, "Disentangling chlorophyll fluorescence from atmospheric scattering effects in O2A-band spectra of reflected sun-light," Geophysical Research Letters, vol. 38, no. 3, pp. 445-456, 2011.

[6] C. Frankenberg, C. O'Dell, J. Berry et al., "Prospects for chlorophyll fluorescence remote sensing from the Orbiting Carbon Observatory-2," Remote Sensing of Environment, vol. 147, pp. 1-12, 2014. 
[7] J. Joiner, L. Guanter, R. Lindstrot et al., "Global monitoring of terrestrial chlorophyll fluorescence from moderate-spectralresolution near-infrared satellite measurements: methodology, simulations, and application to GOME-2," Atmospheric Measurement Techniques, vol. 6, no. 10, pp. 2803-2823, 2013.

[8] J. Joiner, Y. Yoshida, A. P. Vasilkov, Y. Yoshida, L. A. Corp, and E. M. Middleton, "First observations of global and seasonal terrestrial chlorophyll fluorescence from space," Biogeosciences, vol. 8, no. 3, pp. 637-651, 2011.

[9] P. Köhler, C. Frankenberg, T. S. Magney, L. Guanter, J. Joiner, and J. Landgraf, "Global retrievals of solar-induced chlorophyll fluorescence with TROPOMI: first results and intersensor comparison to OCO-2," Geophysical Research Letters, vol. 45, no. 19, pp. 10456-10463, 2018.

[10] T. E. Taylor, A. Eldering, A. Merrelli et al., "OCO-3 early mission operations and initial (vEarly) $\mathrm{XCO}_{2}$ and SIF retrievals," Remote Sensing of Environment, vol. 251, p. 112032, 2020.

[11] E. N. Koffi, P. J. Rayner, A. J. Norton, C. Frankenberg, and M. Scholze, "Investigating the usefulness of satellite-derived fluorescence data in inferring gross primary productivity within the carbon cycle data assimilation system," Biogeosciences, vol. 12, no. 13, pp. 4067-4084, 2015.

[12] J. E. Lee, J. A. Berry, C. van der Tol et al., "Simulations of chlorophyll fluorescence incorporated into the Community Land Model version 4," Global Change Biology, vol. 21, no. 9, pp. 3469-3477, 2015.

[13] N. MacBean, F. Maignan, C. Bacour et al., "Strong constraint on modelled global carbon uptake using solar-induced chlorophyll fluorescence data," Scientific Reports, vol. 8, no. 1, p. 1973, 2018.

[14] A. J. Norton, P. J. Rayner, E. N. Koffi, and M. Scholze, “Assimilating solar-induced chlorophyll fluorescence into the terrestrial biosphere model BETHY-SCOPE v1.0: model description and information content," Geoscientific Model Development, vol. 11, no. 4, pp. 1517-1536, 2018.

[15] X. Wang, J. M. Chen, and W. Ju, "Photochemical reflectance index (PRI) can be used to improve the relationship between gross primary productivity (GPP) and sun-induced chlorophyll fluorescence (SIF)," Remote Sensing of Environment, vol. 246, p. 111888, 2020.

[16] Y. G. Zhang, L. Guanter, J. Joiner, L. Song, and K. Guan, "Spatially-explicit monitoring of crop photosynthetic capacity through the use of space-based chlorophyll fluorescence data," Remote Sensing of Environment, vol. 210, pp. 362-374, 2018.

[17] A. Porcar-Castell, E. Tyystjärvi, J. Atherton et al., "Linking chlorophyll a fluorescence to photosynthesis for remote sensing applications: mechanisms and challenges," Journal of Experimental Botany, vol. 65, no. 15, pp. 4065-4095, 2014.

[18] S. van Wittenberghe, L. Alonso, J. Verrelst, J. Moreno, and R. Samson, "Bidirectional sun-induced chlorophyll fluorescence emission is influenced by leaf structure and light scattering properties - A bottom-up approach," Remote Sensing of Environment, vol. 158, pp. 169-179, 2015.

[19] P. Yang and C. van der Tol, "Linking canopy scattering of farred sun-induced chlorophyll fluorescence with reflectance," Remote Sensing of Environment, vol. 209, pp. 456-467, 2018.

[20] Z. Y. Zhang, J. M. Chen, L. Guanter, L. He, and Y. Zhang, "From canopy-leaving to total canopy far-red fluorescence emission for remote sensing of photosynthesis: first results from TROPOMI," Geophysical Research Letters, vol. 46, no. 21, pp. 12030-12040, 2019.
[21] Z. Y. Zhang, Y. Zhang, J. Joiner, and M. Migliavacca, “Angle matters: bidirectional effects impact the slope of relationship between gross primary productivity and sun-induced chlorophyll fluorescence from Orbiting Carbon Observatory-2 across biomes," Global Change Biology, vol. 24, no. 11, pp. 50175020, 2018.

[22] L. He, J. M. Chen, J. Pisek, C. B. Schaaf, and A. H. Strahler, "Global clumping index map derived from the MODIS BRDF product," Remote Sensing of Environment, vol. 119, pp. 118130, 2012.

[23] X. Liu, L. Guanter, L. Liu et al., "Downscaling of solar-induced chlorophyll fluorescence from canopy level to photosystem level using a random forest model," Remote Sensing of Environment, vol. 231, p. 110772, 2019.

[24] X. Liu, L. Liu, J. Hu, J. Guo, and S. du, "Improving the potential of red SIF for estimating GPP by downscaling from the canopy level to the photosystem level," Agricultural and Forest Meteorology, vol. 281, p. 107846, 2020.

[25] Y. Zeng, G. Badgley, B. Dechant, Y. Ryu, M. Chen, and J. A. Berry, "A practical approach for estimating the escape ratio of near-infrared solar- induced chlorophyll fluorescence," Remote Sensing of Environment, vol. 232, p. 111209, 2019.

[26] Z. Y. Zhang, Y. G. Zhang, A. Porcar-Castell et al., "Reduction of structural impacts and distinction of photosynthetic pathways in a global estimation of GPP from space-borne solarinduced chlorophyll fluorescence," Remote Sensing of Environment, vol. 240, p. 111722, 2020.

[27] C. van der Tol, W. Verhoef, J. Timmermans, A. Verhoef, and Z. Su, "An integrated model of soil-canopy spectral radiances, photosynthesis, fluorescence, temperature and energy balance," Biogeosciences, vol. 6, no. 12, pp. 3109-3129, 2009.

[28] M. Celesti, C. van der Tol, S. Cogliati et al., "Exploring the physiological information of Sun-induced chlorophyll fluorescence through radiative transfer model inversion," Remote Sensing of Environment, vol. 215, pp. 97-108, 2018.

[29] A. Damm, L. Guanter, E. Paul-Limoges et al., "Far-red suninduced chlorophyll fluorescence shows ecosystem-specific relationships to gross primary production: an assessment based on observational and modeling approaches," Remote Sensing of Environment, vol. 166, pp. 91-105, 2015.

[30] J. Pacheco-Labrador, O. Perez-Priego, T. S. el-Madany et al., "Multiple-constraint inversion of SCOPE. Evaluating the potential of GPP and SIF for the retrieval of plant functional traits," Remote Sensing of Environment, vol. 234, p. 111362, 2019.

[31] Y. G. Zhang, L. Guanter, J. A. Berry et al., "Model-based analysis of the relationship between sun-induced chlorophyll fluorescence and gross primary production for remote sensing applications," Remote Sensing of Environment, vol. 187, pp. 145-155, 2016.

[32] M. Meroni, M. Rossini, L. Guanter et al., "Remote sensing of solar-induced chlorophyll fluorescence: review of methods and applications," Remote Sensing of Environment, vol. 113, no. 10, pp. 2037-2051, 2009.

[33] F. Franck, D. Dewez, and R. Popovic, "Changes in the room-temperature emission spectrum of chlorophyll during fast and slow phases of the Kautsky effect in intact leaves," Photochemistry and Photobiology, vol. 81, no. 2, pp. 431436, 2005.

[34] B. Genty, J. Wonders, and N. R. Baker, "Non-photochemical quenching of Fo in leaves is emission wavelength dependent: 
consequences for quenching analysis and its interpretation," Photosynthesis Research, vol. 26, no. 2, pp. 133-139, 1990.

[35] T. S. Magney, C. Frankenberg, P. Köhler et al., "Disentangling changes in the spectral shape of chlorophyll fluorescence: implications for remote sensing of photosynthesis," Journal of Geophysical Research: Biogeosciences, vol. 124, no. 6, pp. 1491-1507, 2019.

[36] J. Verrelst, J. P. Rivera, C. van der Tol, F. Magnani, G. Mohammed, and J. Moreno, "Global sensitivity analysis of the SCOPE model: What drives simulated canopy- leaving sun-induced fluorescence?," Remote Sensing of Environment, vol. 166, pp. 8-21, 2015.

[37] C. Zhang, J. Atherton, J. Peñuelas et al., "Do all chlorophyll fluorescence emission wavelengths capture the spring recovery of photosynthesis in boreal evergreen foliage?," Plant, Cell \& Environment, vol. 42, no. 12, pp. 3264-3279, 2019.

[38] Z. Y. Zhang, Y. G. Zhang, Q. Zhang et al., "Assessing bi-directional effects on the diurnal cycle of measured solar- induced chlorophyll fluorescence in crop canopies," Agricultural and Forest Meteorology, vol. 295, p. 108147, 2020.

[39] P. Köhler, M. J. Behrenfeld, J. Landgraf, J. Joiner, T. S. Magney, and C. Frankenberg, "Global retrievals of solar-induced chlorophyll fluorescence at red wavelengths with TROPOMI," Geophysical Research Letters, vol. 47, no. 15, 2020.

[40] C. van der Tol, "The scattering and re-absorption of red and near-infrared chlorophyll fluorescence in the models Fluspect and SCOPE," Remote Sensing of Environment, vol. 232, p. 111292, 2019.

[41] G. Badgley, C. B. Field, and J. A. Berry, "Canopy near-infrared reflectance and terrestrial photosynthesis," Science Advances, vol. 3, no. 3, article e1602244, 2017.

[42] J. M. Chen and S. G. Leblanc, "Multiple-scattering scheme useful for geometric optical modeling," IEEE Transactions on Geoscience and Remote Sensing, vol. 39, no. 5, pp. 1061-1071, 2001.

[43] K. Oleson, D. M. Lawrence, G. B. Bonan, B. Drewniak, M. Huang, C. D. Koven et al., "Technical description of version 4.5 of the Community Land Model (CLM) (No. NCAR/TN503+STR)," 2013.

[44] C. B. Schaaf, F. Gao, A. H. Strahler et al., "First operational BRDF, albedo nadir reflectance products from MODIS," Remote Sensing of Environment, vol. 83, no. 1-2, pp. 135148, 2002.

[45] A. Lyapustin, J. Martonchik, Y. Wang, I. Laszlo, and S. Korkin, "Multiangle implementation of atmospheric correction (MAIAC): 1. Radiative transfer basis and look-up tables," Journal of Geophysical Research: Atmospheres, vol. 116, no. D3, article D03210, 2011.

[46] A. Lyapustin, Y. Wang, S. Korkin, and D. Huang, "MODIS collection 6 MAIAC algorithm," Atmospheric Measurement Techniques, vol. 11, no. 10, pp. 5741-5765, 2018.

[47] Y. Knyazikhin, J. V. Martonchik, R. B. Myneni, D. J. Diner, and S. W. Running, "Synergistic algorithm for estimating vegetation canopy leaf area index and fraction of absorbed photosynthetically active radiation from MODIS and MISR data," Journal of Geophysical Research: Atmospheres, vol. 103, no. D24, pp. 32257-32275, 1998.

[48] R. B. Myneni, S. Hoffman, Y. Knyazikhin et al., "Global products of vegetation leaf area and fraction absorbed PAR from year one of MODIS data," Remote Sensing of Environment, vol. 83, no. 1-2, pp. 214-231, 2002.
[49] F. Baret, M. Weiss, R. Lacaze et al., "GEOV1: LAI and FAPAR essential climate variables and FCOVER global time series capitalizing over existing products. Part1: Principles of development and production," Remote Sensing of Environment, vol. 137, pp. 299-309, 2013.

[50] F. Camacho, J. Cernicharo, R. Lacaze, F. Baret, and M. Weiss, "GEOV1: LAI, FAPAR essential climate variables and FCOVER global time series capitalizing over existing products. Part 2: validation and intercomparison with reference products," Remote Sensing of Environment, vol. 137, pp. 310-329, 2013.

[51] A. Verger, F. Baret, and M. Weiss, "Near real-time vegetation monitoring at global scale," IEEE Journal of Selected Topics in Applied Earth Observations and Remote Sensing, vol. 7, no. 8, pp. 3473-3481, 2014.

[52] R. Myneni, Y. Knyazikhin, and T. Park, MCD15A2H MODIS/terra+ aqua leaf area index/FPAR 8-day L4 global $500 \mathrm{~m}$ SIN grid V006, Distributed by NASA EOSDIS Land Processes DAAC, 2015.

[53] H. Fang, C. Jiang, W. Li et al., "Characterization and intercomparison of global moderate resolution leaf area index (LAI) products: analysis of climatologies and theoretical uncertainties," Journal of Geophysical Research: Biogeosciences, vol. 118, no. 2, pp. 529-548, 2014.

[54] E. Falge, D. Baldocchi, R. Olson et al., "Gap filling strategies for defensible annual sums of net ecosystem exchange," Agricultural and Forest Meteorology, vol. 107, no. 1, pp. 43-69, 2001.

[55] M. Reichstein, E. Falge, D. Baldocchi et al., "On the separation of net ecosystem exchange into assimilation and ecosystem respiration: review and improved algorithm," Global Change Biology, vol. 11, no. 9, pp. 1424-1439, 2005.

[56] G. J. Collatz, M. Ribas-Carbo, and J. A. Berry, "Coupled photosynthesis-stomatal conductance model for leaves of $\mathrm{C}_{4}$ plants," Functional Plant Biology, vol. 19, no. 5, pp. 519-538, 1992.

[57] R. W. Pearcy and J. Ehleringer, "Comparative ecophysiology of $\mathrm{C}_{3}$ and $\mathrm{C}_{4}$ plants," Plant, Cell \& Environment, vol. 7, no. 1, pp. 1-13, 1984.

[58] L. A. Brown, C. Meier, H. Morris et al., "Evaluation of global leaf area index and fraction of absorbed photosynthetically active radiation products over North America using Copernicus Ground Based Observations for Validation data," Remote Sensing of Environment, vol. 247, p. 111935, 2020.

[59] J. M. Chen, W. Ju, P. Ciais et al., "Vegetation structural change since 1981 significantly enhanced the terrestrial carbon sink," Nature Communications, vol. 10, no. 1, p. 4259, 2019.

[60] P. D'Odorico, A. Gonsamo, B. Pinty et al., "Intercomparison of fraction of absorbed photosynthetically active radiation products derived from satellite data over Europe," Remote Sensing of Environment, vol. 142, pp. 141-154, 2014.

[61] H. Fang, S. Wei, C. Jiang, and K. Scipal, "Theoretical uncertainty analysis of global MODIS, CYCLOPES, and GLOBCARBON LAI products using a triple collocation method," Remote Sensing of Environment, vol. 124, pp. 610621, 2012.

[62] Y. Liu, J. Xiao, W. Ju et al., "Satellite-derived LAI products exhibit large discrepancies and can lead to substantial uncertainty in simulated carbon and water fluxes," Remote Sensing of Environment, vol. 206, pp. 174-188, 2018.

[63] I. McCallum, W. Wagner, C. Schmullius et al., "Comparison of four global FAPAR datasets over Northern Eurasia for the year 
2000," Remote Sensing of Environment, vol. 114, no. 5, pp. 941-949, 2010.

[64] C. A. Pickett-Heaps, J. G. Canadell, P. R. Briggs et al., "Evaluation of six satellite-derived Fraction of Absorbed Photosynthetic Active Radiation (FAPAR) products across the Australian continent," Remote Sensing of Environment, vol. 140, pp. 241-256, 2014.

[65] X. Tao, S. Liang, and D. Wang, “Assessment of five global satellite products of fraction of absorbed photosynthetically active radiation: intercomparison and direct validation against ground-based data," Remote Sensing of Environment, vol. 163, pp. 270-285, 2015.

[66] Z. Xiao, S. Liang, and R. Sun, "Evaluation of three long time series for global fraction of absorbed photosynthetically active radiation (FAPAR) products," IEEE Transactions on Geoscience and Remote Sensing, vol. 56, no. 9, pp. 5509-5524, 2018.

[67] B. Xu, T. Park, K. Yan et al., "Analysis of global LAI/FPAR products from VIIRS and MODIS sensors for spatiotemporal consistency and uncertainty from 2012-2016," Forests, vol. 9, no. 2, p. 73, 2018.

[68] K. Yan, T. Park, G. Yan et al., "Evaluation of MODIS LAI/FPAR product collection 6. Part 2: validation and intercomparison," Remote Sensing, vol. 8, no. 6, p. 460, 2016.

[69] R. Fensholt, I. Sandholt, and S. Stisen, "Evaluating MODIS, MERIS, and VEGETATION vegetation indices using in situ measurements in a semiarid environment," IEEE Transactions on Geoscience and Remote Sensing, vol. 44, no. 7, pp. 17741786, 2006.

[70] C. de Grave, J. Verrelst, P. Morcillo-Pallarés et al., "Quantifying vegetation biophysical variables from the Sentinel-3/FLEX tandem mission: evaluation of the synergy of OLCI and FLORIS data sources," Remote Sensing of Environment, vol. 251, p. 112101, 2020.

[71] Y. Liu, M. J. Hill, X. Zhang et al., "Using data from Landsat, MODIS, VIIRS and PhenoCams to monitor the phenology of California oak/grass savanna and open grassland across spatial scales," Agricultural and Forest Meteorology, vol. 237-238, pp. 311-325, 2017.

[72] E. E. Maeda, Y. M. Moura, F. Wagner et al., "Consistency of vegetation index seasonality across the Amazon rainforest," International Journal of Applied Earth Observation and Geoinformation, vol. 52, pp. 42-53, 2016.

[73] Y. Liu, Z. Wang, Q. Sun et al., "Evaluation of the VIIRS BRDF, Albedo and NBAR products suite and an assessment of continuity with the long term MODIS record," Remote Sensing of Environment, vol. 201, pp. 256-274, 2017.

[74] Z. Wang, C. B. Schaaf, M. J. Chopping et al., "Evaluation of Moderate-resolution Imaging Spectroradiometer (MODIS) snow albedo product (MCD43A) over tundra," Remote Sensing of Environment, vol. 117, pp. 264-280, 2012.

[75] K. Yan, T. Park, C. Chen et al., "Generating global products of LAI and FPAR from SNPP-VIIRS data: theoretical background and implementation," IEEE Transactions on Geoscience and Remote Sensing, vol. 56, no. 4, pp. 2119-2137, 2018.

[76] F. Baret, O. Hagolle, B. Geiger et al., "LAI, fAPAR and fCover CYCLOPES global products derived from VEGETATION: Part 1: Principles of the algorithm," Remote Sensing of Environment, vol. 110, no. 3, pp. 275-286, 2007.

[77] L. B. Hutley, J. Beringer, P. R. Isaac, J. M. Hacker, and L. A. Cernusak, "A sub-continental scale living laboratory: spatial patterns of savanna vegetation over a rainfall gradient in northern Australia," Agricultural and Forest Meteorology, vol. 151, no. 11, pp. 1417-1428, 2011.

[78] L. A. Cernusak, L. B. Hutley, J. Beringer, J. A. M. Holtum, and B. L. Turner, "Photosynthetic physiology of eucalypts along a sub-continental rainfall gradient in northern Australia," Agricultural and Forest Meteorology, vol. 151, no. 11, pp. 14621470, 2011.

[79] J. Beringer, L. B. Hutley, N. J. Tapper, and L. A. Cernusak, "Savanna fires and their impact on net ecosystem productivity in North Australia," Global Change Biology, vol. 13, no. 5, pp. 990-1004, 2007.

[80] J. Beringer, L. B. Hutley, I. McHugh et al., "An introduction to the Australian and New Zealand flux tower network OzFlux," Biogeosciences, vol. 13, no. 21, pp. 5895-5916, 2016.

[81] S. M. Liu, Z. W. Xu, W. Z. Wang et al., "A comparison of eddycovariance and large aperture scintillometer measurements with respect to the energy balance closure problem," Hydrology and Earth System Sciences, vol. 15, no. 4, pp. 1291-1306, 2011.

[82] S. Liu, X. Li, Z. Xu et al., "The Heihe Integrated Observatory Network: a basin-scale land surface processes observatory in China," Vadose Zone Journal, vol. 17, no. 1, p. 180072, 2018.

[83] S. Chen, J. Chen, G. Lin et al., "Energy balance and partition in Inner Mongolia steppe ecosystems with different land use types," Agricultural and Forest Meteorology, vol. 149, no. 11, pp. 1800-1809, 2009.

[84] J. Li, Q. Yu, X. Sun et al., "Carbon dioxide exchange and the mechanism of environmental control in a farmland ecosystem in North China Plain," Science in China Series D: Earth Sciences, vol. 49, no. S2, pp. 226-240, 2006.

[85] T. S. el-Madany, A. Carrara, M. P. Martín et al., "Drought and heatwave impacts on semi-arid ecosystems' carbon fluxes along a precipitation gradient," Philosophical Transactions of the Royal Society B: Biological Sciences, vol. 375, no. 1810, p. 20190519, 2020.

[86] T. S. el-Madany, M. Reichstein, O. Perez-Priego et al., "Drivers of spatio-temporal variability of carbon dioxide and energy fluxes in a Mediterranean savanna ecosystem," Agricultural and Forest Meteorology, vol. 262, pp. 258-278, 2018.

[87] L. A. Cernusak, L. B. Hutley, J. Beringer, J. A. M. Holtum, and B. L. Turner, "Photosynthetic physiology of eucalypts along a sub-continental rainfall gradient in northern Australia," Boreal Environment Research, vol. 151, no. 11, pp. 14621470, 2009.

[88] M. Galvagno, G. Wohlfahrt, E. Cremonese et al., "Phenology and carbon dioxide source/sink strength of a subalpine grassland in response to an exceptionally short snow season," Environmental Research Letters, vol. 8, no. 2, article 025008, 2013.

[89] J. Kurbatova, C. Li, A. Varlagin, X. Xiao, and N. Vygodskaya, "Modeling carbon dynamics in two adjacent spruce forests with different soil conditions in Russia," Biogeosciences, vol. 5, no. 4, pp. 969-980, 2008.

[90] K. S. Hemes, S. D. Chamberlain, E. Eichelmann et al., “Assessing the carbon and climate benefit of restoring degraded agricultural peat soils to managed wetlands," Agricultural and Forest Meteorology, vol. 268, pp. 202-214, 2019.

[91] S. Urbanski, C. Barford, S. Wofsy et al., "Factors controlling $\mathrm{CO}_{2}$ exchange on timescales from hourly to decadal at Harvard Forest," Journal of Geophysical Research: Biogeosciences, vol. 112, no. G2, article G02020, 2007. 
[92] A. E. Suyker and S. B. Verma, "Coupling of carbon dioxide and water vapor exchanges of irrigated and rainfed maize-soybean cropping systems and water productivity," Agricultural and Forest Meteorology, vol. 150, no. 4, pp. 553-563, 2010.

[93] R. Monson, A. A. Turnipseed, J. P. Sparks et al., "Carbon sequestration in a high-elevation, subalpine forest," Global Change Biology, vol. 8, no. 5, pp. 459-478, 2002.

[94] M. Ueyama, H. Iwata, H. Nagano, N. Tahara, C. Iwama, and Y. Harazono, "Carbon dioxide balance in early-successional forests after forest fires in interior Alaska," Agricultural and Forest Meteorology, vol. 275, pp. 196-207, 2019.

[95] A. R. Desai, P. V. Bolstad, B. D. Cook, K. J. Davis, and E. V. Carey, "Comparing net ecosystem exchange of carbon dioxide between an old-growth and mature forest in the upper Midwest, USA," Agricultural and Forest Meteorology, vol. 128, no. 1-2, pp. 33-55, 2005.

[96] S. Ma, D. Baldocchi, S. Wolf, and J. Verfaillie, "Slow ecosystem responses conditionally regulate annual carbon balance over 15 years in Californian oak-grass savanna," Agricultural and Forest Meteorology, vol. 228-229, pp. 252-264, 2016.

[97] B. D. Cook, K. J. Davis, W. Wang et al., "Carbon exchange and venting anomalies in an upland deciduous forest in northern Wisconsin, USA," Agricultural and Forest Meteorology, vol. 126, no. 3-4, pp. 271-295, 2004.

[98] R. L. Scott, E. P. Hamerlynck, G. D. Jenerette, M. S. Moran, and G. A. Barron-Gafford, "Carbon dioxide exchange in a semidesert grassland through drought-induced vegetation change," Journal of Geophysical Research: Biogeosciences, vol. 115, no. G3, article G03026, 2010. 